\title{
Aplicação da Teoria de Filas via Modelagem Computacional em uma Empresa de
}

\section{Lavagem de Veículos}

\author{
Application of Theory of Queues via Computational Modeling in a Vehicle Wash Company \\ Aplicación de la Teoría de Colas via Modelado Computacional en una Empresa de Lavado de \\ Vehículos
}

Recebido: 15/06/2021 | Revisado: 20/06/2021 | Aceito: 26/06/2021 | Publicado: 12/07/2021
Lucas Portes Lacerda
ORCID: https://orcid.org/0000-0001-5558-2931
Universidade Federal dos Vales do Jequitinhonha e Mucuri, Brasil
E-mail: lucas.portes@ufvjm.edu.br
Pedro Ramalho Figueirêdo
ORCID: https://orcid.org/0000-0002-8989-2521
Eniversidade Federal dos Vales do Jequitinhonha e Mucuri, Brasil
E-mail: figueiredo.pedro@ufvjm.edu.br
Alexandre Faissal Brito
ORCID: https://orcid.org/0000-0002-6311-772X
Universidade Federal dos Vales do Jequitinhonha e Mucuri, Brasil
E-mail: alexandre.faissal@ufvjm.edu.br
Jaqueline Maria da Silva
ORCID: https://orcid.org/0000-0002-5713-1533
E-mail: jaqueline.silva@ufvjm.edu.br

\begin{abstract}
Resumo
$\mathrm{Na}$ atualidade, a formação de filas tem sido recorrente para a alocação de recursos, sobretudo, ao considerar cenários de crescente urbanização, uma vez que tais eventos fomentam a formação de filas que estão diretamente relacionadas com a densidade populacional, aumentando assim a competição pelos recursos. Neste contexto, há diversas configurações de filas em setores que são indispensáveis para a população, tornando fundamental a gestão de processos que envolvem filas. Sendo assim, este trabalho propõe a investigação de uma ferramenta para a gestão da capacidade do atendimento em empresas do setor de lavagem de veículos, visando evitar a formação de fillas, que geralmente representam danos para clientes e até mesmo empresas. Esta investigação será feita focando na Teoria das Filas, na Teoria das Restrições e fazendo uso de Modelagem Computacional. À vista disso, objetiva-se evidenciar uma eficaz ferramenta de organização e otimização de processos que envolvem filas.
\end{abstract}

Palavras-chave: Filas, Teoria das filas; Teoria das restrições; Modelagem computacional.

\begin{abstract}
Currently, queuing has been recurrent for resource allocation, especially when considering several growing urbanization scenarios, since such events encourage the queues formation that are directly related to the population density, which increases competition for resources. In this context, there are several configurations of queues in sectors that are indispensable for the population, becoming essential to manage processes that involve queues. Therefore, this work aims to investigate tools for reducing service capacity in companies of the vehicle washing sector, aimed to avoid queues formation, which generally represent damage to customers and even companies. This investigation focuses on the Theory of Queues, the Theory of Constraints and Computational Modeling. The main objective of this research is to show a powerful tool for organizing and optimizing processes that involve queues.
\end{abstract}

Keywords: Queues; Theory of queues; Theory of constraints; Computational modeling.

\section{Resumen}

Actualmente, la formación de colas ha sido recurrente para la asignación de recursos, especialmente al considerar escenarios de creciente urbanización, ya que tales eventos propician la formación de colas que están directamente relacionadas con la densidad poblacional, aumentando así la competencia por los recursos. En este contexto, existen varias configuraciones de colas en sectores que son indispensables para la población, por lo que es fundamental la gestión de procesos que involucran colas. Por ello, este trabajo tiene como objetivo investigar herramientas para la gestión de la capacidad de servicio en empresas del sector de lavado de vehículos, con el objetivo de evitar la formación de colas, que generalmente representan un daño a los clientes e incluso a las empresas. Esta investigación se realizará centrándose en la Teoría de Colas, la Teoría de Restricciones y haciendo uso del Modelado Computacional. Ante esto, el objetivo es mostrar una poderosa herramienta para organizar y optimizar procesos que involucran colas.

Palabras clave: Colas, Teoría de colas; Teoría de restricciones; Modelado computacional. 


\section{Introdução}

O crescimento industrial foi determinante para concentrar um grande número de pessoas nas metrópoles (Simmel, 1987). Este fenômeno de urbanização, acompanhado pelo aumento populacional, impulsiona a formação de filas em alguns setores de prestação de serviços, o que na maior parte das situações reflete em transtornos e prejuízo econômico.

Fenômenos naturais podem ser caracterizados, do ponto de vista de modelagem matemática e computacional, em determinísticos e não determinísticos, que também são chamados de fenômenos estocásticos ou probabilísticos. Os fenômenos determinísticos são caracterizados pela possibilidade da existência de uma solução quando o sistema se encontra em determinadas condições e os não determinísticos são caracterizados pela possibilidade da existência de um conjunto de possíveis resultados (Fogliatti \& Mattos, 2007). Neste contexto, a formação de filas é um fenômeno estocástico característico da sociedade e estudos de gestão de processos envolvendo filas se tornam de grande importância para analisar as situações de forma pontual (Fogliatti \& Mattos, 2007; Silva \& Lacerda, 2019).

A formação de filas ocorre sempre que há oferta de um serviço em que a demanda sobrepõe a capacidade do sistema atendê-la (Sabbadini \& Gonçalves \& De Oliveira, 2006). Isso se dá por inviabilidade econômica, eventuais gargalos do sistema e de limitações do mesmo, além dos fenômenos intrínsecos do corpo social.

Segundo (Camelo et al, 2010), as filas representam um dos sintomas mais visíveis de funcionamento deficiente de um sistema. Então, objetiva-se um balanceamento adequado que permita um atendimento aceitável e que obedeça a relação custobenefício.

A Teoria das Filas surgiu a partir de uma pesquisa desenvolvida em 1909 pelo matemático dinamarquês Agner Krarup Erlang e, desde então, tais estudos se desenvolveram consideravelmente, culminando com vários estudos científicos relacionados em várias áreas de conhecimento.

A Teoria das Restrições iniciou-se a partir de obras do físico israelita Eliyahu Moshe Goldratt, que desenvolveu uma sequência de procedimentos conhecida como "Etapas para Melhoria Contínua". Trata-se de uma estratégia que limita o sistema em estudo para atingir o seu objetivo. Segundo (Goldratt, 1990; 1994), uma restrição não é boa nem má. Ela existe e deve ser gerenciada.

A TOC (Theory of Constraints) foi desenvolvida para obter resultados na indústria. Entretanto, devido a sua simplicidade e eficácia, foi adaptada para diversos setores. A TOC pode melhorar os resultados de qualquer organização, seja ela de produção, serviço ou governamental (De Oliveira, et al, 2020). Alvarez (2012) atesta essa informação e constata que as etapas definidas por Goldratt podem ser usadas perfeitamente em qualquer situação, indo além do gerenciamento e administração de uma fábrica.

Por outro lado, a Modelagem Computacional é uma ferramenta de análise de situações ambientais e sociais de grande importância uma vez que permite a criação de ambientes de simulação em que é possível realizar diversos testes que representam diversos cenários do problema proposto, (Bassanezi, 2002; Kritz, et al, 2012). Permite até mesmo representar a passagem de tempo, como, por exemplo, simular dias de atendimento de uma determinada empresa em poucos minutos.

Como exemplo temos este estudo de análise bibliométrica realizado acerca de modelagem e simulação da secagem de arroz com casca (Venturin \& Silva, 2019). Diversos modelos foram criados na tentativa de otimização deste processo e, segundo o autor, os resultados foram proveitosos e representam evolução na área, no sentido que os modelos contribuem no controle, automatização e na tomada de decisão em processos reais e de grande escala. Ele conclui ainda que a possibilidade de retratar de forma fiel o processo de secagem junto ao baixo custo e tempo de operação são o que tornam as técnicas de modelagem e simulação tão importantes.

A utilização de simulações computacionais é profícua, uma vez que ajuda na tomada de decisão de projetos, elevando o nível de detalhamento do sistema e favorecendo uma melhor visualização de como o sistema se comporta, (Laure, 2019). 
Além disso, é importante pontuar que a tomada de decisões em um sistema real poderia ter consequências negativas, trazendo prejuízo. As simulações computacionais ajudam no estudo detalhado e aprofundado do sistema modelado computacionalmente, de maneira a indicar a melhor opção para implementação das ações em um sistema real. Segundo Banks (2014), a simulação pode ser usada para diversos fins, dentre os quais destaca-se que a simulação permite o estudo e a experimentação das interações internas de um sistema complexo.

O software utilizado para desenvolver o estudo proposto neste texto foi o Arena STUDENT ${ }^{1}$ que é uma versão gratuita disponibilizada para estudantes. Esse programa é composto por um conjunto de blocos utilizados para descrever uma aplicação real e funcionam como comandos de uma linguagem de programação. Os elementos básicos do Arena são as entidades que representam pessoas, objetos, transações, etc. que se movem ao longo do sistema e representam os caminhos que a entidade irá percorrer ao longo das estações (Prado, 1999).

O município de Teófilo Otoni, localizado no estado de Minas Gerais e onde se localiza um dos campi da Universidade Federal dos Vales do Jequitinhonha e Mucuri, tem grande representatividade no cenário regional, principalmente em setores como comércio, ensino, saúde e infraestrutura. Neste contexto, é um importante polo da região dos Vales do Jequitinhonha e do Mucuri, atendendo até mesmo algumas cidades do sul da Bahia e norte do Espírito Santo. Como este município é um estratégico centro regional de convergência de várias demandas, como consequência, vários setores de prestação de serviços do município apresentam a formação de filas.

Considerando o contexto científico proposto, este trabalho aponta um estudo sobre uma metodologia técnicocientífica de análise, visando a organização e a otimização da produtividade dos serviços prestados em duas empresas de lavagem de veículos situadas na cidade de Teófilo Otoni.

Neste contexto, a seção 2 deste trabalho versa sobre a metodologia utilizada para a coleta de dados e a construção do modelo computacional. A seção 3 retrata a discussão dos relatórios obtidos com a compilação do modelo de simulação, bem como a aplicação da Teoria das Restrições. A seção 4 apresenta considerações e resultados a partir do estudo de caso realizado e a contribuição de cada uma das ferramentas utilizadas.

\section{Metodologia}

Este trabalho está relacionado a um estudo de caso que foi realizado em duas empresas do setor de lavagens de veículos localizadas no município de Teófilo Otoni em Minas Gerais. A coleta dos dados foi realizada em nove dias de atendimento em cada uma das empresas, a saber empresas A e B. A coleta de dados foi feita de forma observacional e documental, no sentido de observar e compreender o funcionamento na empresa, registrando todos os horários em que aconteciam atividades relacionadas à lavagem dos veículos.

Ao analisar os dados coletados foi possível realizar algumas considerações relacionadas às etapas dos processos empregados em ambas empresas para a efetivação da lavagem dos veículos. Esses processos são descritos a seguir e representados na Figura 1:

Figura 1: Processos.

Empregados

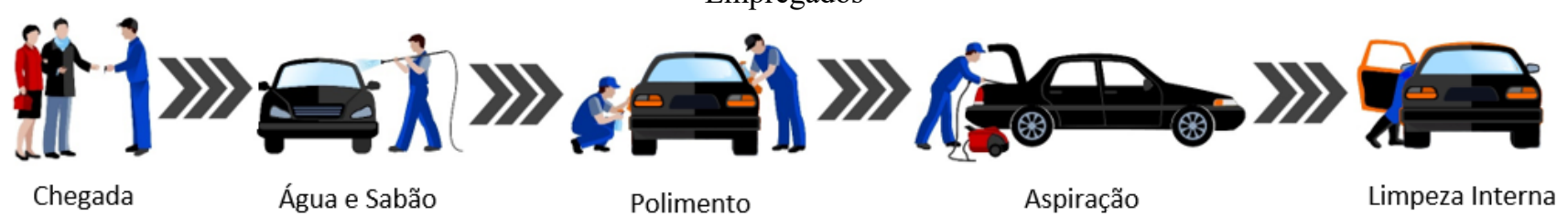

Fonte: Lacerda (2020). 
- Água e Sabão - Processo de lavagem de toda a parte exterior do veículo.

- Polimento - Polimento da parte externa do veículo.

- Aspiração - Remoção dos tapetes e retirada dos bancos para efetuar a aspiração de pó na parte de dentro do automotor.

- Limpeza Interna - Limpeza de bancos, tapetes, cinto de segurança e vidros da parte interna.

Foram realizadas aproximações estatísticas dos tempos de inter chegadas (intervalo de tempo entre as chegadas) e de atendimento de cada processo por meio do "Input Analyzer" do software Arena. Considerando essas relações, foram obtidas expressões matemáticas que melhor representam determinado conjunto de dados, ou seja, que possuem menor erro quadrático. Além disso, o Input Analyser realiza o teste estatístico Kolmogorov-Smirnov, o teste Qui-quadrado e apresenta o p-value. Neste trabalho foi utilizado o teste de Qui-quadrado. Duas hipóteses são levantadas:

• H0: a variável aleatória $\mathrm{X}$ segue a distribuição sob hipótese com os parâmetros estimados

- H1: a variável aleatória X não segue a distribuição sob hipótese com os parâmetros estimados

O valor do nível de significância utilizado foi de $5 \%$ e os valores obtidos para p-value em cada processo são considerados confiáveis dentro dos limites impostos, (Freitas Filho, 2001).

Neste sentido, é importante ressaltar aqui que a Modelagem Computacional muitas vezes pode ser complementada com a Modelagem Matemática, que também é uma representação matemática idealizada de um dado fenômeno do mundo real (Bassanezi, 2002; Doo-Kwon Baik, 2005; Hermann, et al., 2020). O software Arena engloba de forma harmônica estas duas ferramentas de modelagem e essas expressões matemáticas são de grande importância para a configuração do fluxograma lógico da simulação.

\section{Criação de um modelo Computacional}

Os resultados apresentados nesta seção retratam o início da elaboração do modelo computacional construído com o software Arena. O esquema apresentado na Figura 2 a seguir é a representação do fluxo lógico de atendimento empregado nas empresas A e B.

Figura 2: Fluxograma.

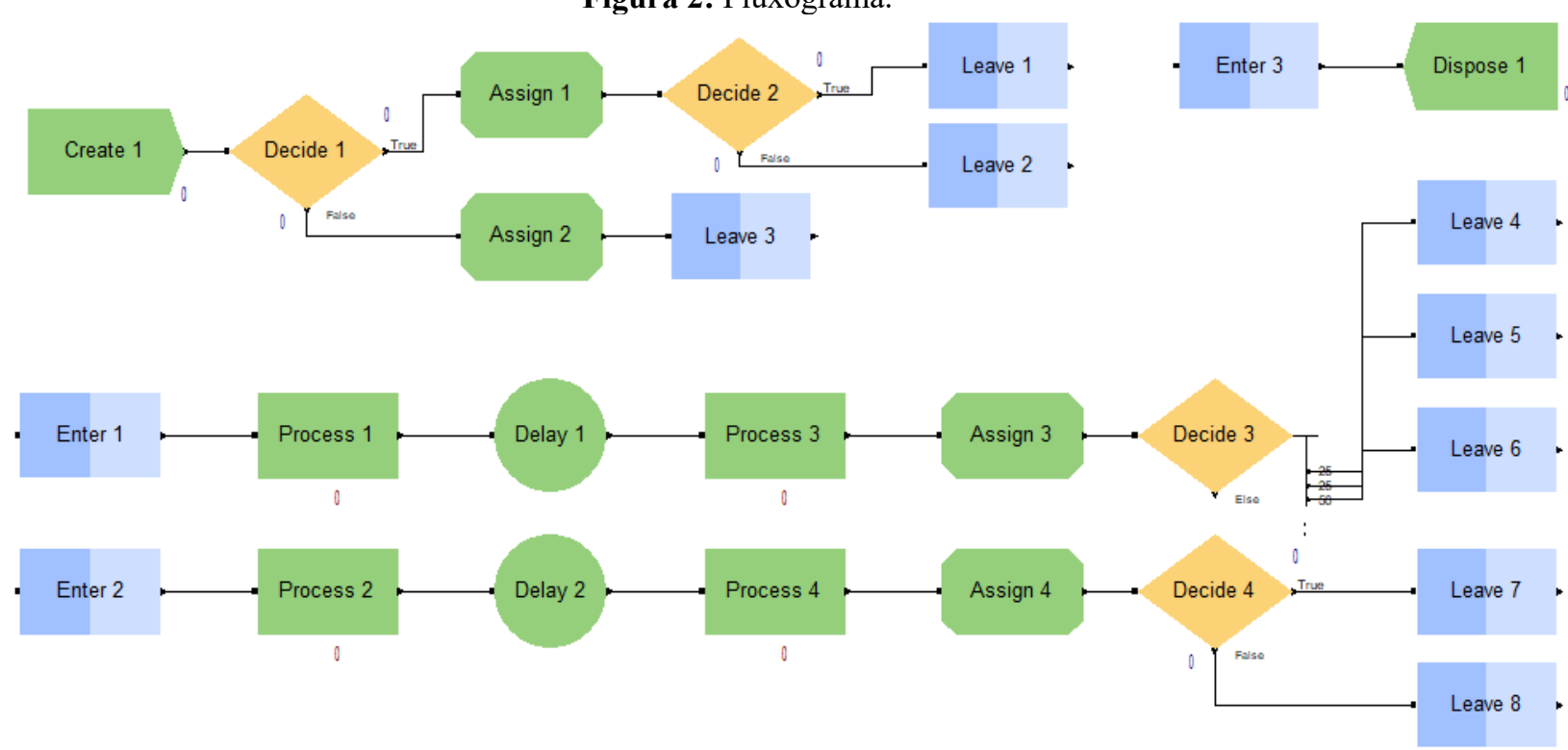

Fonte: Autores (2021). 
É importante pontuar que esta seção também retrata o mapeamento e a representação do processo, desde a chegada até a saída do sistema, passo a passo, seguindo uma ligação lógica de construção do modelo de simulação representado na Figura 2.

Passo 1: O primeiro elemento é o Create, representando o início das atividades e descrevendo o processo de chegada do veículo na empresa. Arrastando o bloco Create para a área de trabalho, em seguida dê dois cliques obtém-se a janela de configuração do bloco, representada pela Figura 3 a seguir:

Figura 3: Configuração bloco Create.

\begin{tabular}{|c|c|c|c|c|c|}
\hline \multicolumn{2}{|l|}{ Create } & & & $?$ & X \\
\hline \multicolumn{3}{|l|}{ Name: } & \multicolumn{3}{|c|}{ Entity Type: } \\
\hline \multicolumn{2}{|l|}{ Chegada } & $\checkmark$ & \multicolumn{2}{|l|}{ Entity 1} & $\checkmark$ \\
\hline \multicolumn{6}{|l|}{ Time Between Arrivals } \\
\hline Type: & \multicolumn{2}{|l|}{ Value: } & \multicolumn{3}{|l|}{ Units: } \\
\hline Random (Expo) $\quad \checkmark$ & \multicolumn{2}{|l|}{1} & \multicolumn{2}{|l|}{ Hours } & $\checkmark$ \\
\hline Entities per Arrival: & \multicolumn{2}{|l|}{ Max Arrivals: } & \multicolumn{3}{|c|}{ First Creation: } \\
\hline 1 & \multicolumn{2}{|l|}{ Infinite } & \multicolumn{3}{|l|}{0.0} \\
\hline \multicolumn{6}{|l|}{ Comment: } \\
\hline & OK & & hcelar & & \\
\hline
\end{tabular}

Fonte: Autores (2021).

São definidos o nome do bloco, o tipo de entidades. A "Expression" (expressão) que descreve melhor os dados foi obtida pela aproximação realizada pelo recurso "Input Analyzer" nas empresas A e B. Neste seguimento, a expressão obtida para as empresas A e B são respectivamente: $-0.001+148 * \operatorname{BETA}(0.996,4.62)$ e $-0.001+136 * \operatorname{BETA}(0.994,3.3)$.

Passo 2: O segundo elemento é o bloco Decide, que tem o papel de diferenciar qual veículo que chega na empresa. Nesse sentido, para configurar o bloco se faz necessário a utilização da função "2-way by Chance". Essa função é moldada atribuindo-se o percentual de veículos que são classificados como carros ou motos.

Na Empresa A foram atendidos 198 veículos, sendo 9 motocicletas, ou seja, 95,45\% dos veículos atendidos são carros e o complementar motos (4,55\%). A Empresa B atendeu 107 veículos, sendo 2 motocicletas. Assim, 1,87\% são motos e $98,13 \%$ são carros. A Figura 4 a seguir ilustra a proporção de carros e motos nas empresas. 
Figura 4: Percentual de carros e motos

\section{EMPRESA A}

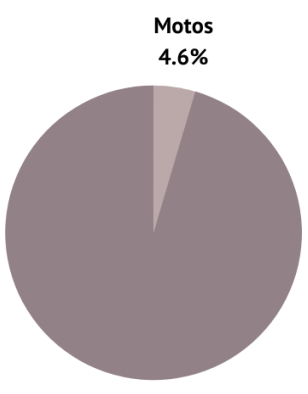

Carros

$95.5 \%$
EMPRESA B

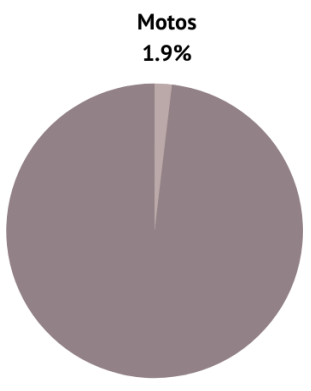

Carros

Fonte: Autores (2021).

Passo 3: O próximo bloco a compor o fluxograma é o Assign, que pode determinar muitas características das entidades (veículos). Por esse motivo o bloco está em seguida da diferenciação atribuída no Passo 2 como mostra a Figura 5 a seguir.

Figura 5: Construção do Fluxograma - Adição dos Blocos Assign.

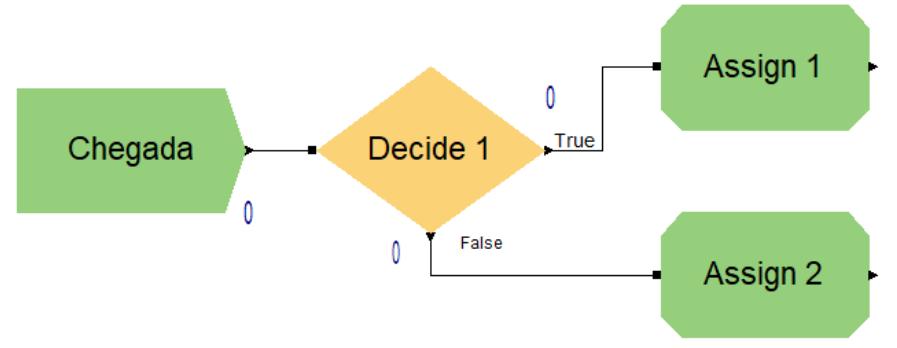

Fonte: Autores (2021).

O Assign vai determinar imagens para representar um carro e uma moto, para que seja possível diferenciar as entidades quando a simulação estiver compilando. Além disso, acrescenta-se um contador para a entidade motocicleta. Isso se dá pelo fato que a moto não passa por todos os processos. Ela passa apenas pelos processos considerados externos, que são "Água e Sabão"e "Aspiração".

O módulo "Assign 1" que está representado na Figura 6 especifica a imagem da entidade, sendo assim o bloco é nomeado como "Imagem Carro". Clicando na opção "Adicionar" podemos criar um atributo para imagem. Além do mais, atribui-se em "Type" a opção Entity Picture e seleciona-se uma imagem. Para visualizar as imagens disponíveis no Arena, deve-se clicar em Editar/Desenhos/Entidades. 
Figura 6: Configuração Bloco Assign 1.

\begin{tabular}{|c|c|c|c|c|}
\hline Assign & & & $?$ & X \\
\hline \multicolumn{5}{|l|}{ Name: } \\
\hline Imagem Carro & & $\checkmark$ & & \\
\hline \multicolumn{5}{|l|}{ Assignments: } \\
\hline \multirow{3}{*}{$\begin{array}{l}\text { Entity Picture, Picture. Blue Ball } \\
\text { <End of list }>\end{array}$} & & & Adicionar... & \\
\hline & & & Editar... & \\
\hline & & & \multirow[t]{2}{*}{ Excluir } & \\
\hline \multicolumn{3}{|l|}{ Comment: } & & \\
\hline & OK & Cancelar & Ajuda & \\
\hline
\end{tabular}

Fonte: Autores (2021).

O bloco "Assign 2" tem o papel de mudança de imagem e adição de um contador. Para tal, basta repetir o processo feito no bloco "Assign 1"com a adição da capacidade de contagem. Além disso, para adição do contador basta clicar em "Adicionar" e em seguida atribui-se em "Type" a opção Attribute e define o nome de uma variável e em "New Value", que estabelece um mecanismo de contador toda vez que uma entidade passa por esse bloco.

Passo 4: O próximo módulo a compor o fluxograma desempenha um papel importante na simulação. O bloco Decide tem o papel de distinguir as diferentes sequências de atendimento baseando-se em percentuais obtidos com a investigação dos dados coletados. A finalidade desse bloco é representar as diferentes sequências de atendimento empregadas em ambas empresas. Trata-se de deliberações por parte dos responsáveis pela execução dos processos que tem como objetivo mitigar os efeitos da fila. O módulo Decide vai intercalar os carros por duas sequências distintas, conforme elucida as Figuras 7 e 8 , relativas à Empresa $\mathrm{A}$ e à Empresa $\mathrm{B}$, respectivamente.

Figura 7: Configuração bloco Decide Empresa A.

EMPRESA A

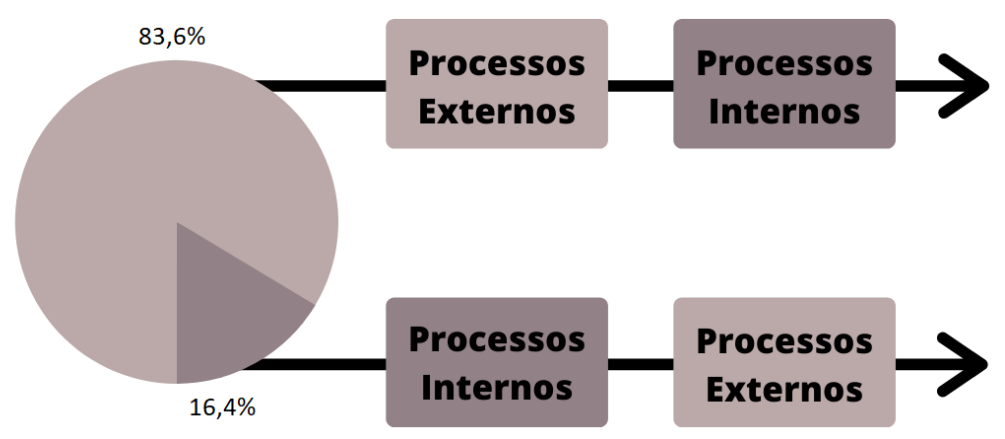

Fonte: Autores (2021).

Conforme representado na Figura 7, os percentuais de atendimento para a empresa A são; 83,6\% dos atendimentos ocorrem dos processos externos para os processos internos e 16,4\% de processos internos para externos. Já para a empresa B $53,33 \%$ dos atendimentos ocorrem de processos externos para internos, enquanto $46,67 \%$ são de processos internos para 
externos, conforme está representado na Figura 8.

Figura 8: Configuração bloco Decide Empresa B.

EMPRESA B

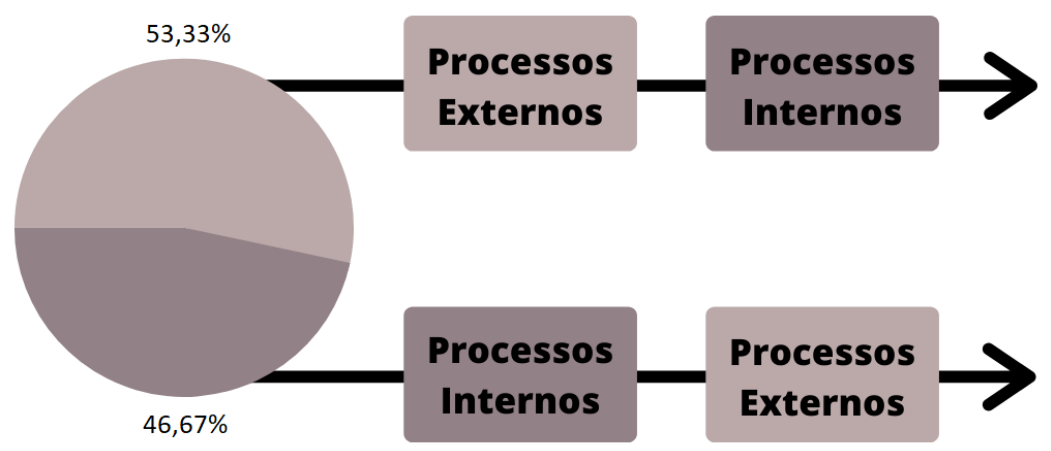

Fonte: Autores (2021).

A Figura 9 representa a adição do módulo Decide. Para configurar o bloco, basta repetir o processo descrito no Passo 2, alterando o nome do bloco nomeado para "Sequência" com as probabilidades especificadas na Figura 7 para o modelo de simulação da empresa A e na Figura 8 para o modelo da empresa B.

Figura 9: Construção do Fluxograma - Adição do bloco Decide.

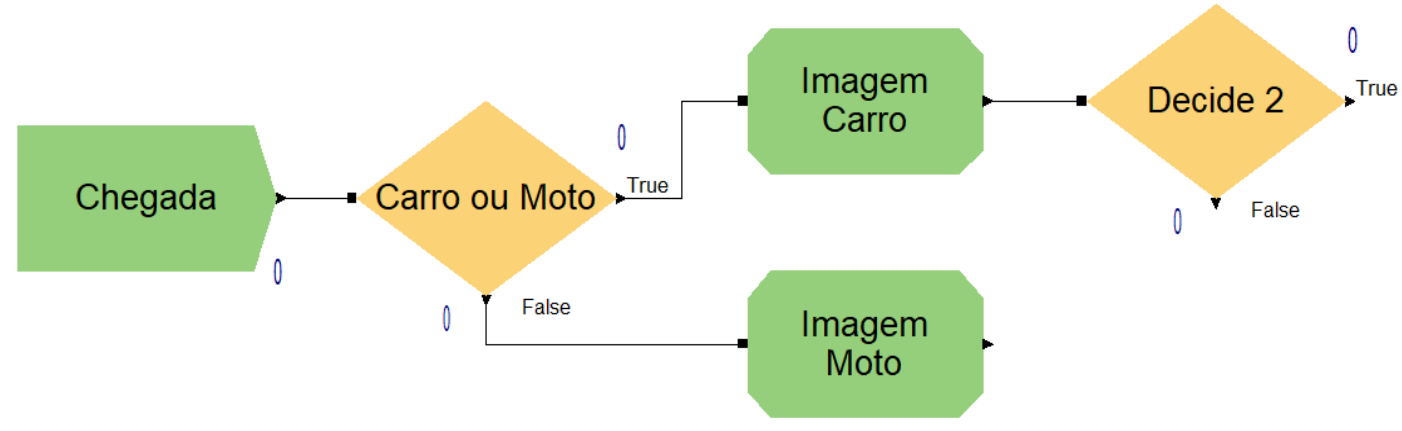

Fonte: Autores (2021).

Passo 5: Esta etapa compreende na criação de alguns blocos que vão encaminhar às entidades para as estações de trabalho, bem como a criação de estações.

O bloco responsável por encaminhar as entidades é o bloco Leave, que determina uma rota até a estação de trabalho desejada. Além disso, o bloco pode representar o tempo inerente à metodologia de atendimento adotada nas empresas. Esses intervalos podem ser considerados como tempo de transferência de um setor da empresa para outro.

Para considerar os tempos de transferência é fundamental considerar os veículos que não sofrem influência da fila, ou seja, é um intervalo de tempo constante relativo à organização física dos setores nas empresas. Para criar essas estações utilizase o módulo Enter, esse bloco determina a entrada da estação de trabalho. A Figura 10 a seguir é uma representação do fluxograma com a adição desses módulos. 
Figura 10: Construção do Fluxograma - Adição dos blocos Leave e Enter.

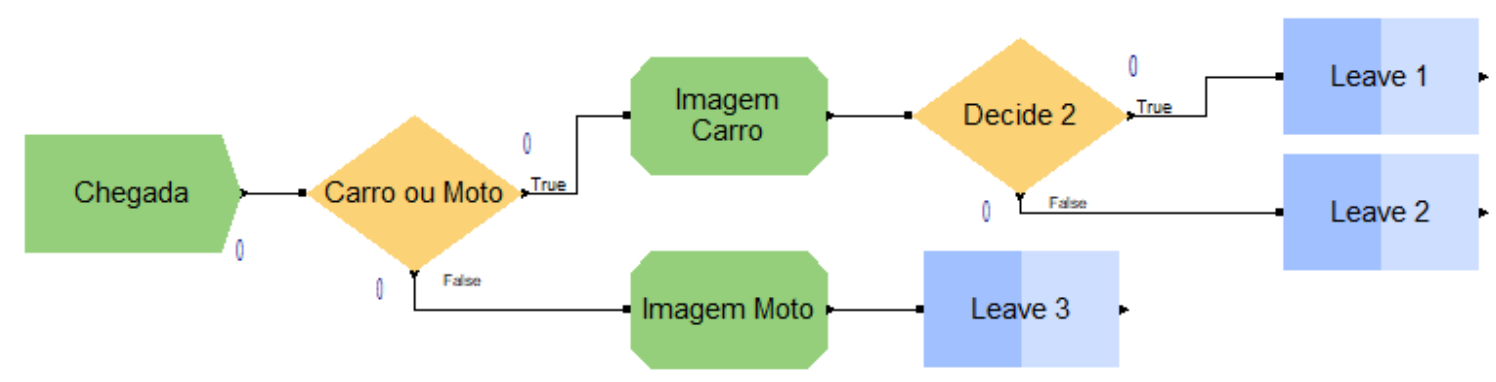

Enter 1

Fonte: Autores (2021).

Os blocos Leave vão determinar para qual estação a entidade será encaminhada. O bloco Leave 3 representado na Figura 10 transfere as motocicletas para a estação de entrada dos processos externos. Já os módulos Leave 1 e Leave 2 transferem os carros de forma a mesclar a sequência de atendimento com base nas especificações atribuídas ao bloco Decide (Sequência). Além disso, atribui-se na função "Move Time" o tempo de transferência constante de 2 minutos.

A configuração dos blocos Enter basicamente consiste em definir o nome do bloco e o nome da estação. Neste sentido, o bloco "Enter 1" é referente ao Trabalho Externo, enquanto o "Enter 2" está relacionado com o Trabalho Interno.

Passo 6: Este passo compreende a configuração dos processos de atendimento da empresa. Neste sentido, configurase quatro blocos Process interligados aos blocos Enter. Ademais, são criados dois blocos Delay para representar o tempo de transferência. A Figura 11 a seguir representa o fluxograma com formatação realizada. 
Figura 11: Construção do Fluxograma.
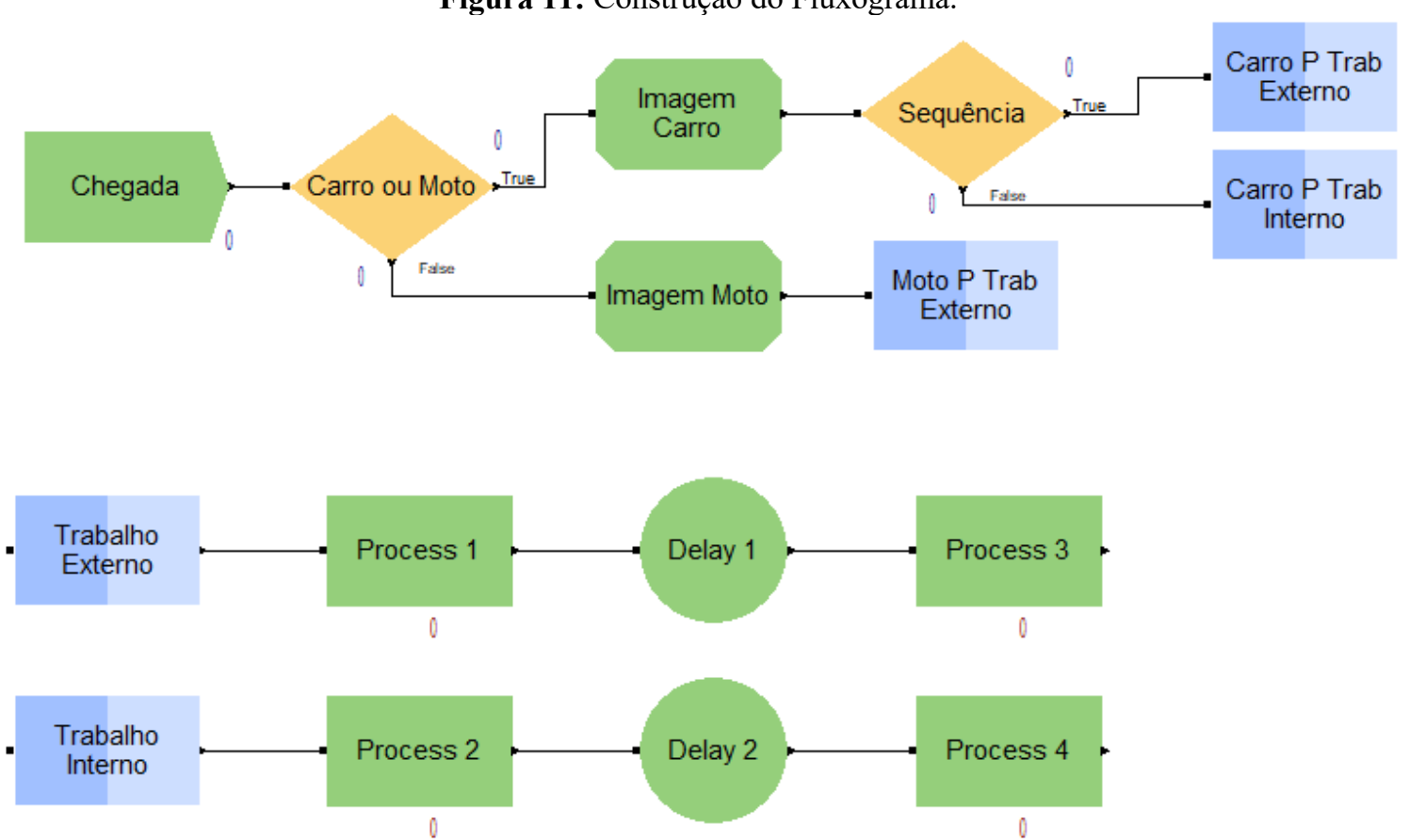

Fonte: Autores (2021).

Os módulos "Process 1", "Process 2", "Process 3" e "Process 4" representam os processos de atendimento água e sabão, aspiração, polimento e limpeza interna, respectivamente. Os dados do bloco Process precisam ser alterados. Para modificar as propriedades do bloco Process, basta dar um duplo clique, especifique o nome do processo. Em Delay Type, atribui-se o valor Expression que são as expressões obtidas com o Input Analyzer representados na Tabela 1 a seguir.

Nas representações das expressões matemáticas há algumas abreviações. O termo "GAMM" remete-se a distribuição de probabilidade Gamma, "WEIB" corresponde a distribuição Weibull, "LOGN" trata-se da distribuição Lognormal, "POIS" retrata a distribuição de Poisson, "NORM" refere-se a distribuição Normal e por fim "BETA" remete a distribuição Beta.

Tabela 1: Expressões Input Analyzer.

\begin{tabular}{ccc} 
Processos & Empresa A & Empresa B \\
Água e Sabão & $13.5+\operatorname{GAMM}(4.32,4.32)$ & $\operatorname{NORM}(30,7.66)$ \\
Aspiração & $8.5+\operatorname{WEIB}(10.8,2.26)$ & $8.5+22 * \operatorname{BETA}(2.53,3.03)$ \\
Polimento & $4.5+\operatorname{LOGN}(12.4,6.11)$ & $7.5+\operatorname{GAMM}(2.97,3.17)$ \\
Limpeza Interna & POIS(17.1) & $7.5+24 * \operatorname{BETA}(2.9,3.18)$ \\
& \multicolumn{2}{c}{ Fonte: Autores (2021). }
\end{tabular}

Além disso, em Units, basta selecionar a unidade de tempo Minutes. Atribui-se em Action, no grupo Logic, o valor Seize Delay Release e adiciona-se um recurso para o processo. Para configurar os blocos Delay basta atribuir os nomes "Transferência 1"e "Transferência 2". Além disso, determinar 1.5 minutos de transferência conforme está representado na Figura 12 a seguir: 
Figura 12: Configuração bloco Delay.

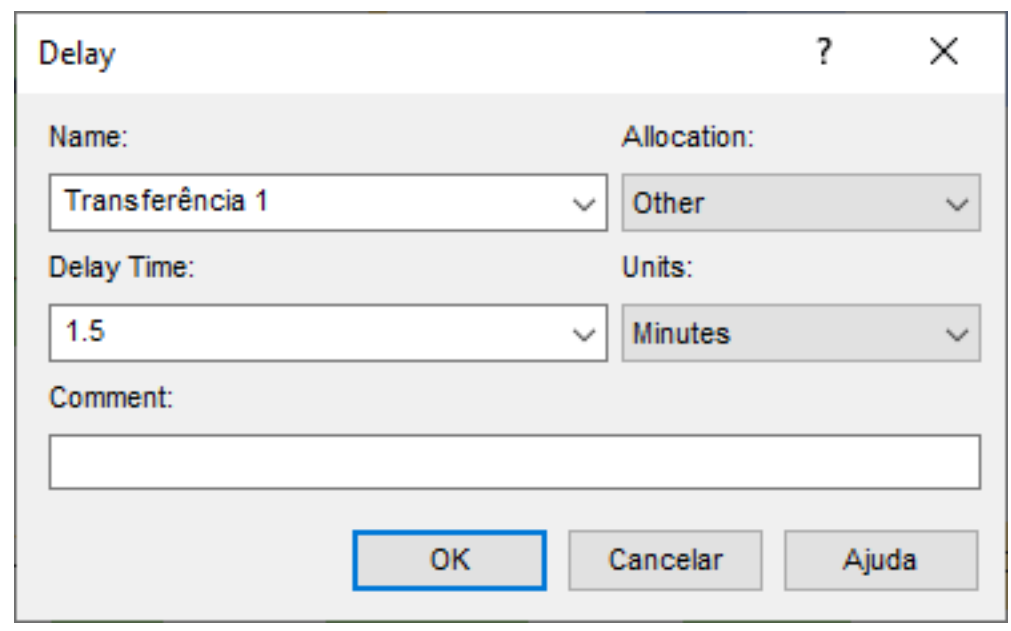

Fonte: Autores (2021).

Passo 7: Essa etapa corresponde à configuração dos blocos Assign. Esses blocos exercem o papel de contador, ou seja, uma engrenagem lógica para representar as entidades que já passaram por processos. A Figura 13 a seguir é uma representação do fluxograma com a adição dos blocos Assign.

Figura 13: Construção do Fluxograma.
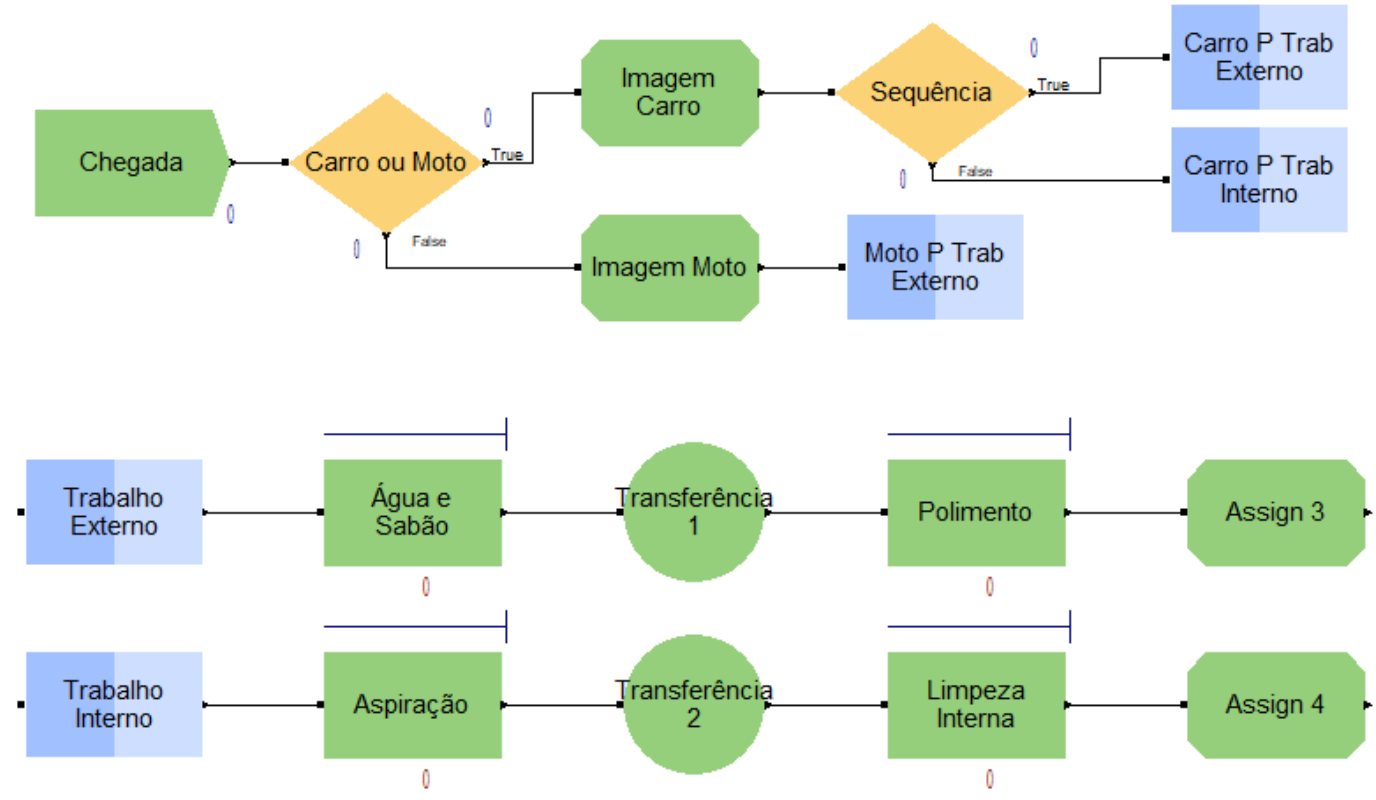

Fonte: Autores (2021).

Para configurar os módulos Assign é necessário determinar uma tarefa que é adicionar um contador à variável "Processo". A Figura 14 a seguir elucida como é a configuração do bloco Assign. 
Figura 14: Configuração bloco Assign.

\begin{tabular}{|c|c|c|c|c|}
\hline Assign & & & $?$ & $\times$ \\
\hline \multicolumn{5}{|l|}{ Name: } \\
\hline Contador 1 & & $\checkmark$ & & \\
\hline \multicolumn{5}{|l|}{ Assignments: } \\
\hline \multirow{3}{*}{\begin{tabular}{|l|} 
Attribute, Processo, Processo $0+2$ \\
<End of list
\end{tabular}} & & & \multicolumn{2}{|l|}{ Adicionar... } \\
\hline & & & Editar... & \\
\hline & & & Excluir & \\
\hline \multicolumn{4}{|l|}{ Comment: } & \\
\hline & $\mathrm{OK}$ & Cancelar & Ajuda & \\
\hline
\end{tabular}

Fonte: Autores (2021).

Passo 8: Essa etapa consiste na adição de dois blocos Decide. A Figura 15 é uma representação do fluxograma.

Figura 15: Construção do Fluxograma.
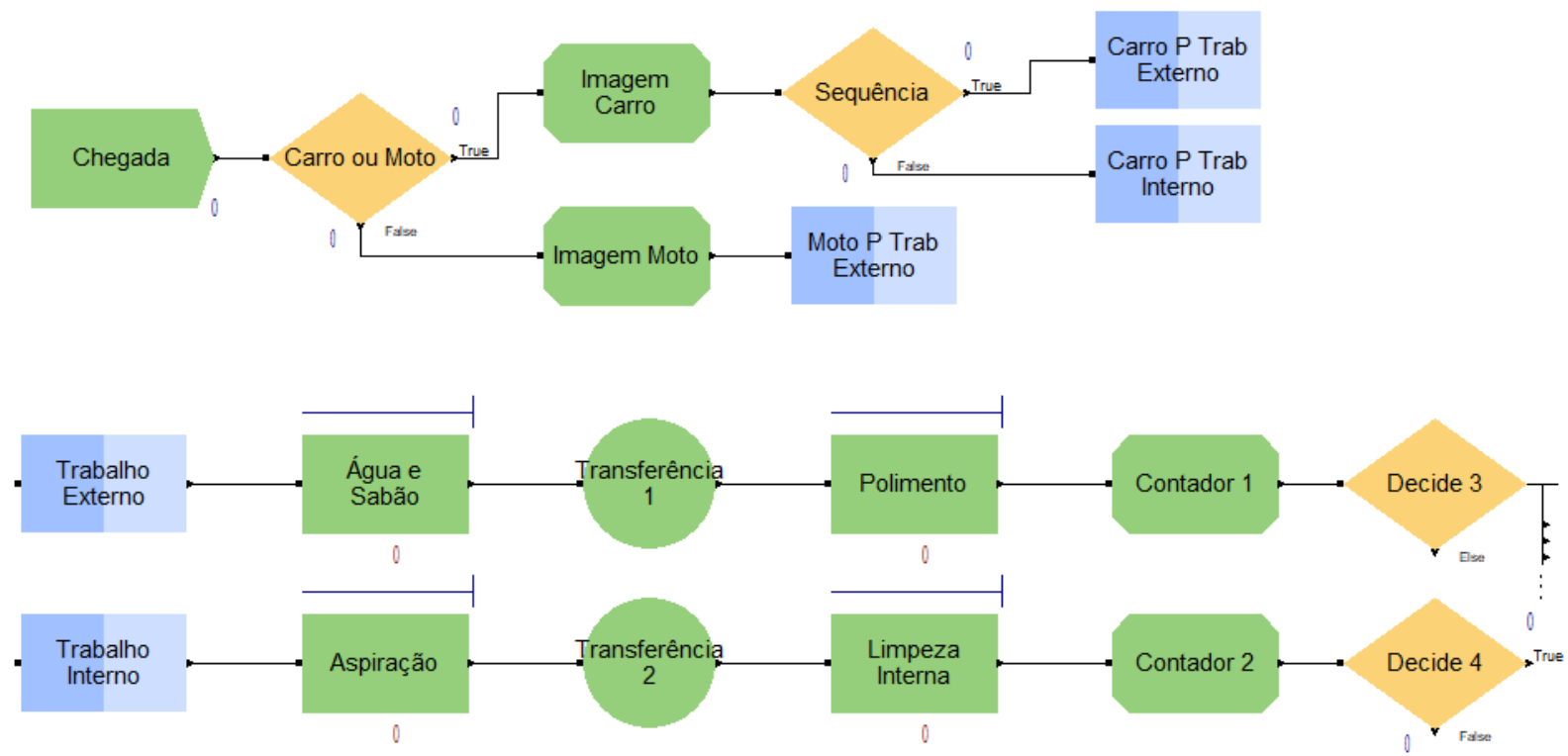

Fonte: Autores (2021).

O papel do bloco Decide é verificar a contagem da variável "Processo" das entidades. Com isso é possível encaminhar os veículos para a saída ou para os processos que ainda não foram submetidos. O bloco "Decide 3", um dos blocos representados na Figura 15 está interligado com a estação de trabalho denominada "Trabalho Externo", por isso há três possíveis situações.

Situação 1: A entidade em questão é uma motocicleta que possui variável Processo $=3$. Sendo que ao passar pelos blocos "Imagem moto" adquiriu valor 1 e no bloco "contador 1" mais 2.

Situação 2: A entidade é um carro que ainda não foi submetido a todos os processos e precisa ser encaminhado para a estação "Trabalho Interno". Possuindo valor da variável Processo = 2, adquirido ao passar pelo bloco "Contador 1".

Situação 3: A entidade em questão é um carro que já passou pela estação "Trabalho Interno" e os processos da estação "Trabalho Externo", ou seja, já foi atendido e está com a variável Processo $=4$. Visto que adquiriu esse quantitativo 
passando pelos blocos "Contador 1" e "Contador 2". Neste sentido, deve-se moldar o bloco "Decide 3" com esses parâmetros. Para tal, é crucial adotar uma linguagem computacional evidenciada no Quadro 1 para configurar essas situações.

Quadro 1: Linguagem Computacional.

\begin{tabular}{|c|c|c|}
\hline Linguagem Computacional & Matemática Tradicional & Significado \\
\hline .LT. (less than) & $<$ & Menor que \\
\hline .LE. (less than or equal to) & $\leq$ & Menor ou igual que \\
\hline .EQ. (equal to) & $\neq$ & Igual a \\
\hline .NE. (not equal to) & $>$ & Diferente de \\
\hline .GT. (greater than) & $\geq$ & Maior que \\
\hline .GE. (greater than or equal to) & & Maior ou igual que \\
\hline
\end{tabular}

Fonte: Autores (2021).

A configuração do bloco Decide 3 está representada na Figura 16 a seguir:

Figura 16: Configuração do bloco Decide 3.

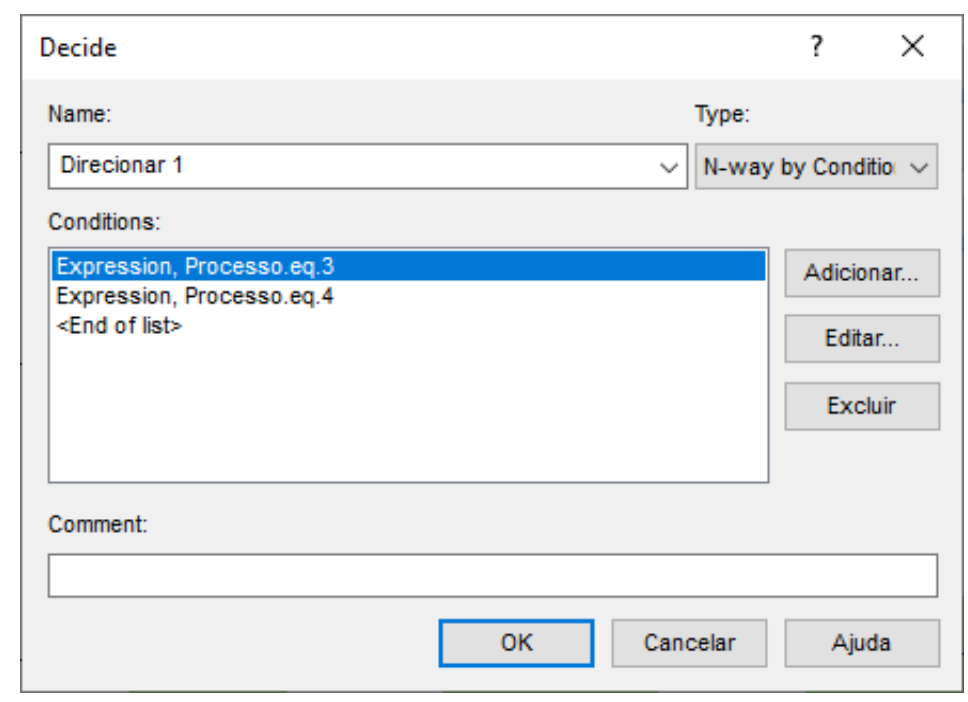

Fonte: Autores (2021).

De forma geral o bloco tem duas condições de saída do sistema que são representadas na Figura 16 referente às situações 1 e 2. Faz parte das características de configuração do bloco Decide a estrutura de decisão encadeada, ou seja, se não atender nenhuma das condições atribuídas o software automaticamente interpreta que se trata de outra condição, no caso a situação 3. A configuração do bloco Decide 4 abrange duas possíveis situações:

Situação 1: Entidade em estudo é um carro com variável Processo $=2$. Sendo que adquiriu esse valor ao passar pelo bloco "Contador 2".

Situação 2: Entidade em questão é um carro com variável Processo = 4, ou seja, já passou por todos os processos de atendimento. Haja vista que, adquiriu esse valor passando pelos Contadores 1 e 2 .

O bloco Decide 4 é configurado de forma similar ao Decide 3, porém com menos uma situação. A Figura 17 a seguir 
é uma representação da configuração deste bloco.

Figura 17: Configuração bloco Decide 4.

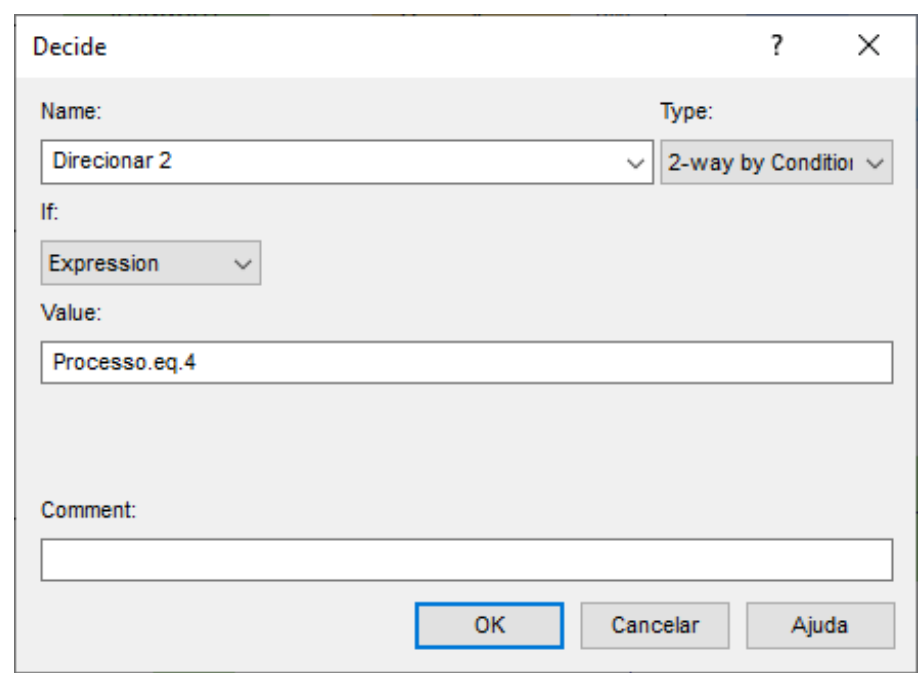

Fonte: Autores (2021).

Além disso, os blocos Decide 3 e Decide 4, respectivamente, são nomeados como "Direcionar 1" e "Direcionar 2".

Passo 9: Essa etapa é compreendida pela adição dos blocos Enter e Dispose. A Figura 18 a seguir é uma representação do fluxograma com a adição dos blocos.

Figura 18: Construção do Fluxograma.
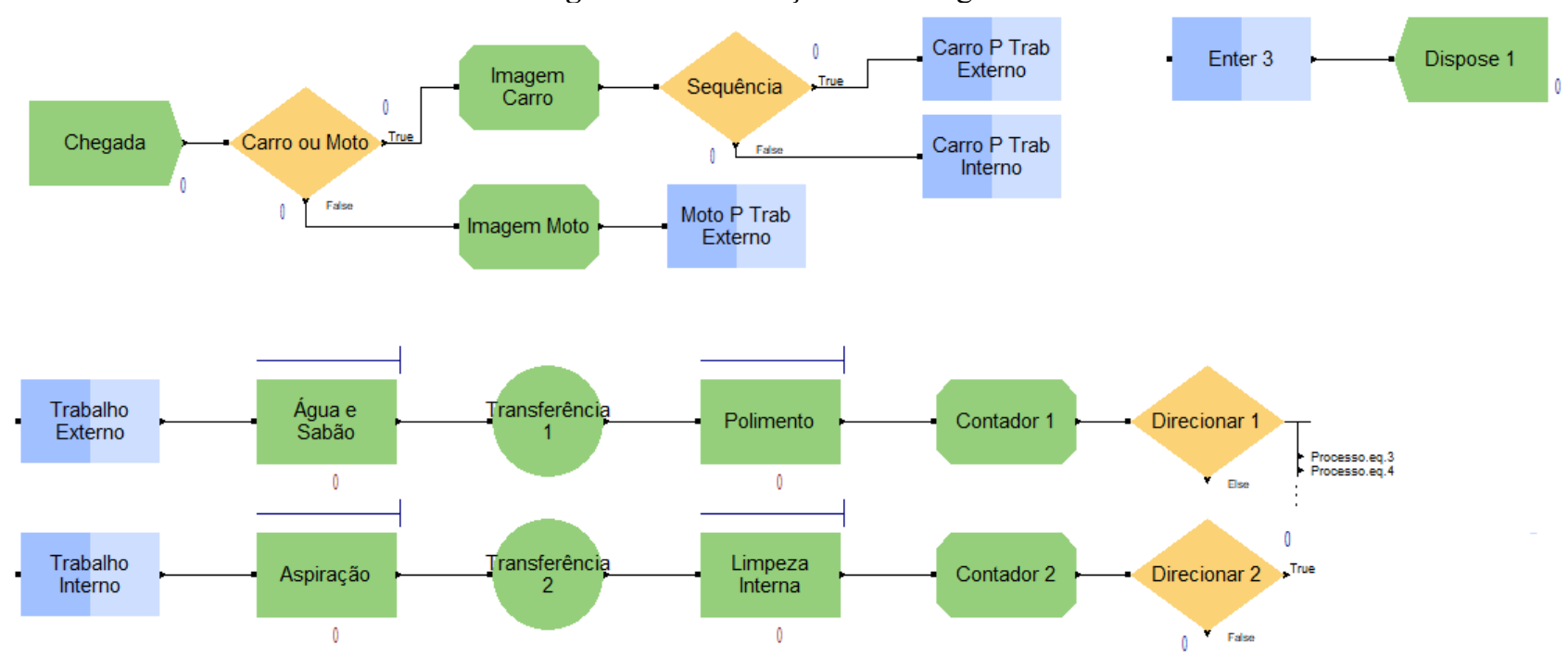

Fonte: Autores (2021).

A estação de saída do sistema é composta de dois blocos, sendo estes o Enter 3 e Dispose 1. Para configurar esses blocos basta definir os nomes como "Deslocamento" e "Saída". Além disso, definir o nome da estação ao clicar duas vezes sobre o bloco Enter.

Passo 10: Essa etapa é compreendida pela adição dos blocos Leave. Como em alguns passos anteriores, o bloco Leave desempenhou o papel de encaminhar as entidades para outras estações e determinar uma taxa de transferência. A Figura 19 a seguir é uma representação do fluxograma com a adição dos blocos. 
Figura 19: Construção do Fluxograma.

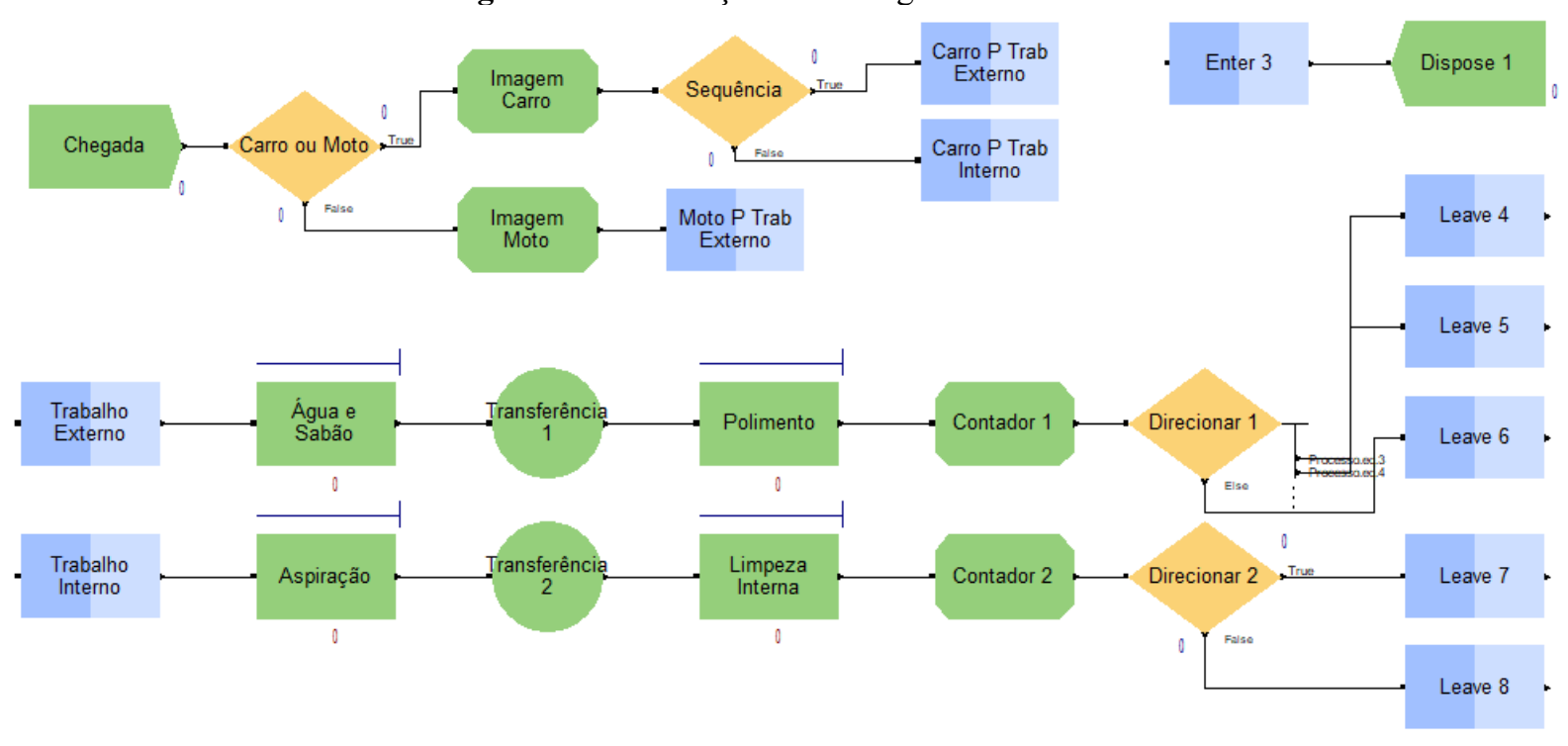

Fonte: Autores (2021).

De acordo com a configuração dos blocos Decide no passo 8 e a representação na Figura 19, é imperativo considerar que os blocos Leave empenham a função de encaminhar para duas estações, sendo essas uma de saída do sistema e outra mudança de estação de trabalho.

O bloco Leave 4 está interligado à situação 1 descrita na configuração do bloco "Direcionar 1", portanto seu papel é encaminhar as motocicletas à saída do sistema. Nesse sentido, o bloco foi nomeado como "Moto p Saída" e sua configuração é remeter a estação de saída e atribuir 1.5 minutos de transição.

Assim como o bloco Leave 4 os demais blocos foram moldados baseando-se nas condições atribuídas nas configurações dos blocos Direcionar 1 e 2.

\section{Resultados e Discussões}

\subsection{Resultados das Simulações}

Ao final da compilação dos modelos computacionais desenvolvidos, o software Arena gera um relatório com diversas análises estatísticas do modelo de simulação que são de grande relevância para o estudo de desempenho de ambas empresas.

\subsubsection{Análise do Relatório - Empresa A}

Para compilar o modelo de simulação foram definidas as horas de atendimento da empresa que corresponde às 11 horas por dia. Além disso, simulou-se o equivalente a 300 dias de serviço.

As informações contidas no relatório contribuem para uma visão sistêmica de como é a rotina de trabalho de cada empresa. É possível analisar diversos parâmetros como o número médio de atendimentos de veículos por dia, informações relacionadas aos tempos de valor agregado ou tempo que o veículo estava sendo processado, tempos de espera, tempos de transferência e o tempo total de atendimento.

Ademais, algumas características específicas da empresa também são auferidas no relatório da simulação tais como, número médio de entidades que entraram no sistema, que saíram do sistema e os que ficaram sendo processados ao final da simulação. Outrossim, analisar quais processos tiveram maior tempo de espera e veículos nas filas e por fim o tempo de execução de cada processo. A Quadro 2 a seguir apresenta algumas informações extraídas do relatório de atividades da Empresa A: 
Quadro 2: Relatório da Empresa A.

\begin{tabular}{|c|c|c|c|}
\hline \multicolumn{4}{|c|}{ Característica Geral do Sistema - Empresa A } \\
\hline \multicolumn{2}{|c|}{ Número médio de atendimento } & \multicolumn{2}{|l|}{ 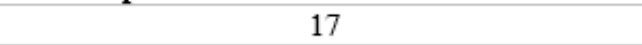 } \\
\hline Tempo & Média & Média Mínima & Média Máxima \\
\hline Tempo de valor agregado & 1hora $22 \mathrm{~min} 24 \mathrm{~s}$ & 1hora $11 \mathrm{~min} 44 \mathrm{~s}$ & 1hora $31 \mathrm{~min} 56 \mathrm{~s}$ \\
\hline Tempo de Espera & 1hora $11 \mathrm{~min} 29 \mathrm{~s}$ & $3 \min 56 s$ & 2 horas $59 \mathrm{~min} 9 \mathrm{~s}$ \\
\hline Tempo de Transferência & $4 \min 55 \mathrm{~s}$ & $4 \mathrm{~min} 39 \mathrm{~s}$ & $5 \min$ \\
\hline Outros & $2 \min 56 \mathrm{~s}$ & $2 \min 39 \mathrm{~s}$ & $3 \mathrm{~min}$ \\
\hline Total Time & 2 horas $41 \min 44 \mathrm{~s}$ & 1hora $26 \min 28 \mathrm{~s}$ & 4 horas $32 \mathrm{~min} 34 \mathrm{~s}$ \\
\hline Características específicas & Média & Média Mínima & Média Máxima \\
\hline $\begin{array}{l}\text { Número de entidades que } \\
\text { entraram no sistema }\end{array}$ & 26,150 & 13,000 & 38,000 \\
\hline $\begin{array}{l}\text { Número de entidades que } \\
\text { saíram no sistema }\end{array}$ & 17,137 & 10,000 & 21,000 \\
\hline $\begin{array}{l}\text { Trabalho em } \\
\text { desenvolvimento }\end{array}$ & 5,978 & 1,628 & 13,373 \\
\hline \multicolumn{4}{|c|}{ Características da Fila } \\
\hline Tempo de Espera & Média & Média Mínima & Média Máxima \\
\hline Água e Sabão & 1hora $16 \mathrm{~min} 57 \mathrm{~s}$ & $6 \min 9 s$ & 3horas $15 \mathrm{~min} 2 \mathrm{~s}$ \\
\hline Aspiração & $2 \min 58 \mathrm{~s}$ & 0 & 1hora $3 \min 9 \mathrm{~s}$ \\
\hline Limpeza Interna & $1 \mathrm{~min} 1 \mathrm{~s}$ & 0 & $26 \mathrm{~min} 14 \mathrm{~s}$ \\
\hline Polimento & $21 \mathrm{~s}$ & 0 & $27 \mathrm{~min} 59 \mathrm{~s}$ \\
\hline Tamanho da Fila & Média & Média Mínima & Média Máxima \\
\hline Água e Sabão & 3,2234 & 0,1442 & 10,4665 \\
\hline Aspiração & 0,0891 & 0 & 0,5726 \\
\hline Limpeza Interna & 0,0294 & 0 & 0,2793 \\
\hline Polimento & 0,0105 & 0 & 0,1091 \\
\hline \multicolumn{4}{|c|}{ Taxa de Utilização dos Recursos - Tempo de Atendimento } \\
\hline Processos & Média & Média Mínima & Média Máxima \\
\hline Água e Sabão & $56 \mathrm{~min} 28 \mathrm{~s}$ & $34 \mathrm{~min} 20 \mathrm{~s}$ & $59 \mathrm{~min} 49 \mathrm{~s}$ \\
\hline Aspiração & $30 \mathrm{~min} 18 \mathrm{~s}$ & $14 \mathrm{~min} 50 \mathrm{~s}$ & $38 \mathrm{~min} 52 \mathrm{~s}$ \\
\hline Limpeza Interna & $27 \mathrm{~min} 39 \mathrm{~s}$ & $15 \mathrm{~min} 55 \mathrm{~s}$ & $36 \mathrm{~min} 25 \mathrm{~s}$ \\
\hline Polimento & $28 \mathrm{~min} 28 \mathrm{~s}$ & $15 \mathrm{~min} 49 \mathrm{~s}$ & $38 \mathrm{~min} 33 \mathrm{~s}$ \\
\hline
\end{tabular}

Fonte: Autores (2021).

Ao comparar as informações de todos os processos, observa-se que o processo "Água e Sabão" é improficiente, apresentando os maiores valores de tempo de espera, veículos na fila e tempo de execução. No sentido de avaliar os processos de atendimento, o Gráfico 1 a seguir mostra a Taxa de utilização dos recursos da empresa A.

Segundo Goldratt (1990; 1994), as restrições do sistema determinam o desempenho do sistema e tais limitações podem ser identificadas pelas longas filas de espera e o maior tempo de processamento. Com base na representação do Gráfico 1 é possível identificar que a restrição ou gargalo do sistema é o processo "Água e Sabão" por ter o maior tempo de processamento. 
Gráfico 1: Taxa de Utilização dos Processos da Empresa A.

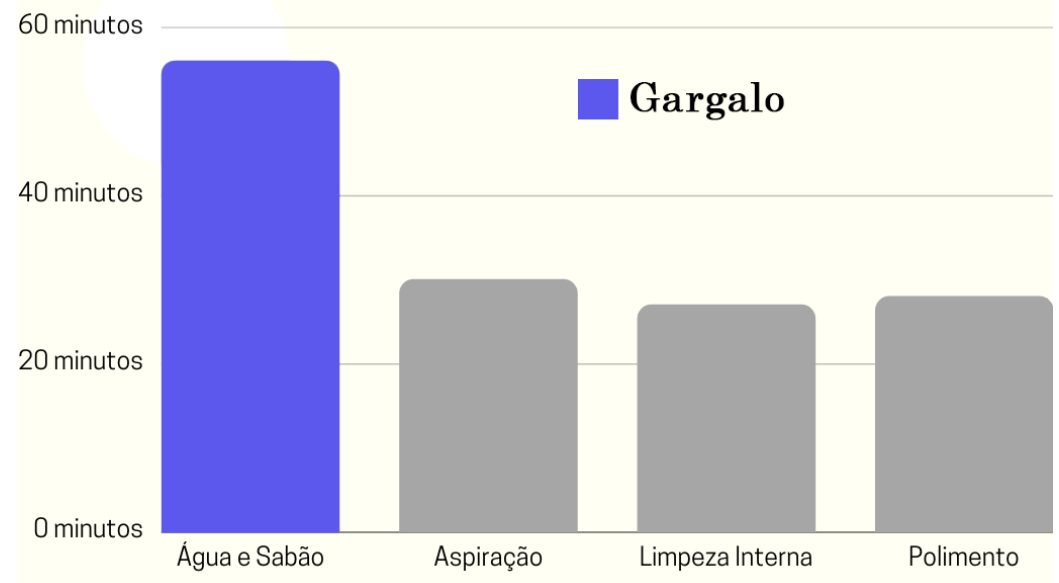

Fonte: Autores (2021).

Seguindo a premissa de Goldratt, de que a restrição é um fator que limita a empresa atingir sua meta, deve-se considerar propostas de otimização atuando na diminuição no tempo de atendimento do processo "Água e Sabão". Para tal, aplica-se às etapas de melhoria definidas por Goldratt.

\subsubsection{Análise do Relatório - Empresa B}

Para compilar o modelo de simulação foram definidas as horas de atendimento da empresa que corresponde à 8 horas por dia, além disso, foi atribuída a replicação do equivalente a 300 dias de serviço.

O relatório da empresa B tem algumas aproximações quando comparado com as informações do relatório da Empresa A. Principalmente quando analisado o processo "Água e Sabão" que apresentou maior improficiência com os maiores valores de tempo de espera, veículos na fila e tempo de execução.

O Quadro 3 a seguir representa algumas informações extraídas do relatório do Arena. Para analisar o tempo de execução dos processos e apontar a restrição do modelo da empresa B, o gráfico apresentado no Gráfico 2 a seguir mostra a taxa de utilização dos recursos. 
Quadro 3: Relatório da Empresa B.

\begin{tabular}{|c|c|c|c|}
\hline \multicolumn{4}{|c|}{ Característica Geral do Sistema - Empresa B } \\
\hline \multicolumn{2}{|c|}{ Número médio de atendimento } & \multicolumn{2}{|c|}{11} \\
\hline Tempo & Média & Média Mínima & Média Máxima \\
\hline Tempo de valor agregado & 1hora $23 \mathrm{~min} 41 \mathrm{~s}$ & 1hora $10 \mathrm{~min} 2 \mathrm{~s}$ & 1hora $35 \mathrm{~min} 26 \mathrm{~s}$ \\
\hline Tempo de Espera & $34 \mathrm{~min} 9 \mathrm{~s}$ & $2 \min 30 \mathrm{~s}$ & 2 horas $8 \mathrm{~min} 7 \mathrm{~s}$ \\
\hline Tempo de Transferência & $4 \mathrm{~min} 58 \mathrm{~s}$ & $4 \mathrm{~min} 32 \mathrm{~s}$ & $5 \mathrm{~min}$ \\
\hline Outros & $2 \min 58 \mathrm{~s}$ & $2 \mathrm{~min} 32 \mathrm{~s}$ & $3 \min$ \\
\hline Total Time & 2 horas $5 \mathrm{~min} 45 \mathrm{~s}$ & 1hora $28 \mathrm{~min} 24 \mathrm{~s}$ & 3horas $44 \mathrm{~min} 31 \mathrm{~s}$ \\
\hline Características especificas & Média & Média Mínima & Média Máxima \\
\hline $\begin{array}{l}\text { Número de entidades que } \\
\text { entraram no sistema }\end{array}$ & 16,0733 & 9,0000 & 24,0000 \\
\hline $\begin{array}{l}\text { Número de entidades que } \\
\text { sairam no sistema }\end{array}$ & 11,2033 & 5,0000 & 15,0000 \\
\hline $\begin{array}{l}\text { Trabalho em } \\
\text { desenvolvimento }\end{array}$ & 3,8297 & 1,5162 & 10,3974 \\
\hline \multicolumn{4}{|c|}{ Características da Fila } \\
\hline Tempo de Espera & Média & Média Mínima & Média Máxima \\
\hline Água e Sabão & $30 \mathrm{~min} 46 \mathrm{~s}$ & $2 \min 11 \mathrm{~s}$ & 2 horas $4 \mathrm{~min} 22 \mathrm{~s}$ \\
\hline Aspiração & $5 \min 48 s$ & 0 & $26 \mathrm{~min} 14 \mathrm{~s}$ \\
\hline Limpeza Interna & $2 \min 1 \mathrm{~s}$ & 0 & $12 \mathrm{~min} 48 \mathrm{~s}$ \\
\hline Polimento & $1 \mathrm{~s}$ & 0 & $3 \min 26 s$ \\
\hline Tamanho da Fila & Média & Média Mínima & Média Máxima \\
\hline Água e Sabão & 1,0766 & 0,0498 & 6,3426 \\
\hline Aspiração & 0,1816 & 0 & 0,9840 \\
\hline Limpeza Interna & 0,0601 & 0 & 0,4529 \\
\hline Polimento & 0,0084 & 0 & 0,1072 \\
\hline \multicolumn{4}{|c|}{ Taxa de Utilização dos Recursos - Tempo de Atendimento } \\
\hline Processos & Média & Média Mínima & Média Máxima \\
\hline Água e Sabão & $49 \min 5 \mathrm{~s}$ & $24 \mathrm{~min} 9 \mathrm{~s}$ & $59 \mathrm{~min} 45 \mathrm{~s}$ \\
\hline Aspiração & $31 \mathrm{~min} 22 \mathrm{~s}$ & $18 \mathrm{~min} 7 \mathrm{~s}$ & $47 \mathrm{~min} 36 \mathrm{~s}$ \\
\hline Limpeza Interna & $30 \mathrm{~min} 13 \mathrm{~s}$ & $14 \mathrm{~min} 31 \mathrm{~s}$ & $47 \mathrm{~min} 20 \mathrm{~s}$ \\
\hline Polimento & $26 \min 4 s$ & $10 \mathrm{~min} 49 \mathrm{~s}$ & $39 \min 2 \mathrm{~s}$ \\
\hline
\end{tabular}

Fonte: Autores (2021).

Analisando o Gráfico 2 é possível observar que ambas empresas precisam de intervenções no processo "Água e Sabão".

Gráfico 2: Taxa de Utilização dos Processos da Empresa B.

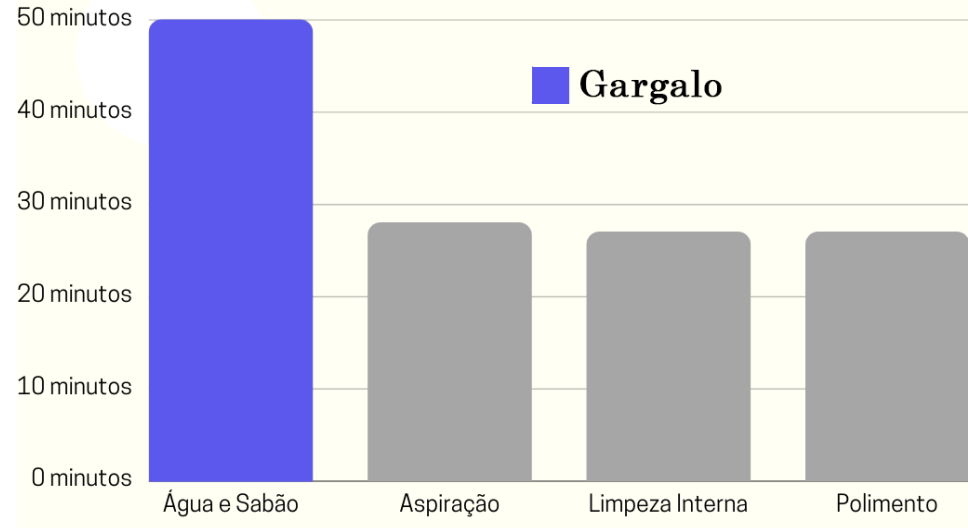


Goldratt faz uma analogia entre uma empresa e uma corrente para descrever esse caráter sistêmico das relações. Quando se traciona uma corrente ela sempre quebrará em seu elo mais fraco, ou seja, no elo que apresentar a maior restrição de força. Logo, se queremos aumentar a resistência da corrente, devemos concentrar esforços para reforçar o elo mais fraco. Nas palavras de Goldratt, isso significa "elevar a restrição". A restrição de um sistema define seu desempenho. Para aumentar o desempenho do sistema é necessário então primeiro identificar a restrição e então explorá-la para que possa ser elevada. Aumentar a resistência de qualquer outro elo da corrente, que não a restrição, não irá gerar melhoria na capacidade da corrente em sustentar carga, ou seja, não se estará gerando melhoria no sistema, (Figueiredo, 2010).

\subsection{Aplicação da Teoria das Restrições}

Esta seção apresenta uma aplicação das etapas definidas por Goldratt para melhoria contínua de um sistema produtivo. É relevante considerar que as operações possuem recursos humanos, máquinas e equipamentos que permitem atender uma certa quantidade de veículos em um determinado intervalo de tempo, em função da capacidade de cada um. Para encontrar uma alternativa para agilizar o sistema, é imperativo aplicar os passos para sua melhoria contínua, conforme segue:

Passo 1: Identificação das restrições. Com base nos dados que foram coletados, foi realizada a simulação da execução das etapas dos trabalhos das empresas e determinadas as restrições dos sistemas de atendimento. Observou-se que a operação com maior tempo de processamento foi “Água e Sabão”, ou seja, esta operação é o gargalo do sistema.

Passos 2 e 3: Decisões sobre como explorar as restrições existentes no sistema. Nessas duas etapas investiga-se ao máximo as peculiaridades do gargalo do sistema. Isso significa fazer a restrição funcionar em função do objetivo da empresa que é lavar o maior número de veículos em menos tempo, de forma a atender bem a demanda dos clientes. Assim, uma forma de executar essa fase, seria o agendamento do atendimento baseado na capacidade de atendimento do processo "Água e Sabão". Deste modo, o processo estaria operando no máximo de sua capacidade.

Passo 4: Melhoria da capacidade das restrições do sistema. Essa fase consiste em determinar uma estratégia objetivando o aumento da capacidade de atendimento do gargalo. Nesse sentido, uma boa estratégia de intervenção seria concentrar os servidores na etapa "Água e Sabão", no intuito de aumentar a capacidade de operação da restrição, desocupando a plataforma onde ocorre o processo, de forma que o veículo subsequente possa ser submetido a essa etapa.

Passo 5: Reavaliação do sistema para checar a existência de novas restrições. Caso o sistema ainda apresenta uma restrição, todo o processo é refeito, retornando para o passo 1.

\subsubsection{Novas Simulações: Aumento da capacidade de atendimento dos gargalos do sistema}

Para avaliar melhor a proposta de concentrar os operários na restrição do sistema, é fundamental a realização de uma nova simulação das empresas. A alternância da capacidade do processo "Água e Sabão" nas empresas A e B é baseada na quantidade de trabalhadores. A grosso modo, essa intervenção consiste em priorizar o atendimento no processo mais demorado. Haja vista que, a Empresa A contava com média de 7 funcionários e a empresa B com 4. O Quadro 4 a seguir representa informações relacionadas ao novo relatório do Arena para a empresa A. 
Quadro 4: Relatório Simulação da Intervenção da Empresa A.

\begin{tabular}{|c|c|c|c|}
\hline \multicolumn{4}{|c|}{ Característica Geral do Sistema - Empresa A } \\
\hline \multicolumn{2}{|c|}{ Número médio de atendimento } & \multicolumn{2}{|l|}{ 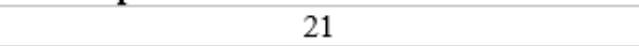 } \\
\hline Tempo & Média & Média Mínima & Média Máxima \\
\hline Tempo de valor agregado & 1hora $22 \mathrm{~min} 24 \mathrm{~s}$ & 1hora $15 \mathrm{~min} 33 \mathrm{~s}$ & 1hora $31 \mathrm{~min} 32 \mathrm{~s}$ \\
\hline Tempo de Espera & $21 \mathrm{~min} 5 \mathrm{~s}$ & $1 \mathrm{~min} 38 \mathrm{~s}$ & 1hora $7 \mathrm{~min} 51 \mathrm{~s}$ \\
\hline Tempo de Transferência & $4 \mathrm{~min} 55 \mathrm{~s}$ & $4 \mathrm{~min} 41 \mathrm{~s}$ & $5 \mathrm{~min}$ \\
\hline Outros & $2 \min 56 \mathrm{~s}$ & $2 \mathrm{~min} 41 \mathrm{~s}$ & $3 \mathrm{~min}$ \\
\hline Total Time & 1hora $51 \mathrm{~min} 21 \mathrm{~s}$ & 1hora $28 \mathrm{~min} 9 \mathrm{~s}$ & 2 horas $37 \mathrm{~min} 54 \mathrm{~s}$ \\
\hline Características específicas & Média & Média Mínima & Média Máxima \\
\hline $\begin{array}{l}\text { Número de entidades que } \\
\text { entraram no sistema }\end{array}$ & 26,003 & 14,000 & 36,000 \\
\hline $\begin{array}{l}\text { Número de entidades que } \\
\text { sairam no sistema }\end{array}$ & 21,473 & 10,000 & 30,000 \\
\hline $\begin{array}{l}\text { Trabalho em } \\
\text { desenvolvimento }\end{array}$ & 4,104 & 1,622 & 7,504 \\
\hline \multicolumn{4}{|c|}{ Características da Fila } \\
\hline Tempo de Espera & Média & Média Mínima & Média Máxima \\
\hline Água e Sabão & $6 \min 9 \mathrm{~s}$ & 0 & $29 \min 19 \mathrm{~s}$ \\
\hline Aspiração & $7 \min 6 \mathrm{~s}$ & $32 \mathrm{~s}$ & $29 \min 27 \mathrm{~s}$ \\
\hline Limpeza Interna & $2 \min 3 s$ & 0 & $13 \min 26 \mathrm{~s}$ \\
\hline Polimento & $6 \mathrm{~min} 55 \mathrm{~s}$ & $14 s$ & $32 \mathrm{~min} 51 \mathrm{~s}$ \\
\hline Tamanho da Fila & Média & Média Mínima & Média Máxima \\
\hline Água e Sabão & 0,2618 & 0 & 1,5469 \\
\hline Aspiração & 0,2634 & 0,0129 & 1,2582 \\
\hline Limpeza Interna & 0,0721 & 0 & 0,5697 \\
\hline Polimento & 0,2687 & 0,0055 & 1,5064 \\
\hline \multicolumn{4}{|c|}{ Taxa de Utilização dos Recursos - Tempo de Atendimento } \\
\hline Processos & Média & Média Mínima & Média Máxima \\
\hline Água e Sabão & $30 \mathrm{~min} 53 \mathrm{~s}$ & $13 \min 47 \mathrm{~s}$ & $45 \min 18 \mathrm{~s}$ \\
\hline Aspiração & $36 \mathrm{~min} 17 \mathrm{~s}$ & $17 \mathrm{~min} 12 \mathrm{~s}$ & $56 \mathrm{~min} 10 \mathrm{~s}$ \\
\hline Limpeza Interna & $32 \min 55 \mathrm{~s}$ & $16 \mathrm{~min} 27 \mathrm{~s}$ & $48 \mathrm{~min} 57 \mathrm{~s}$ \\
\hline Polimento & $36 \mathrm{~min} 4 \mathrm{~s}$ & $17 \mathrm{~min} 42 \mathrm{~s}$ & $52 \mathrm{~min} 48 \mathrm{~s}$ \\
\hline
\end{tabular}

Fonte: Autores (2021).

Com base no Quadro 4 é possível concluir que o tempo de execução do gargalo melhorou significativamente, assim como o tempo de espera. A análise do Gráfico 3 apresentado a seguir mostra a taxa de utilização para investigação de desempenho e a identificação de um novo gargalo do sistema.

Gráfico 3: Novo Gargalo da Empresa A.

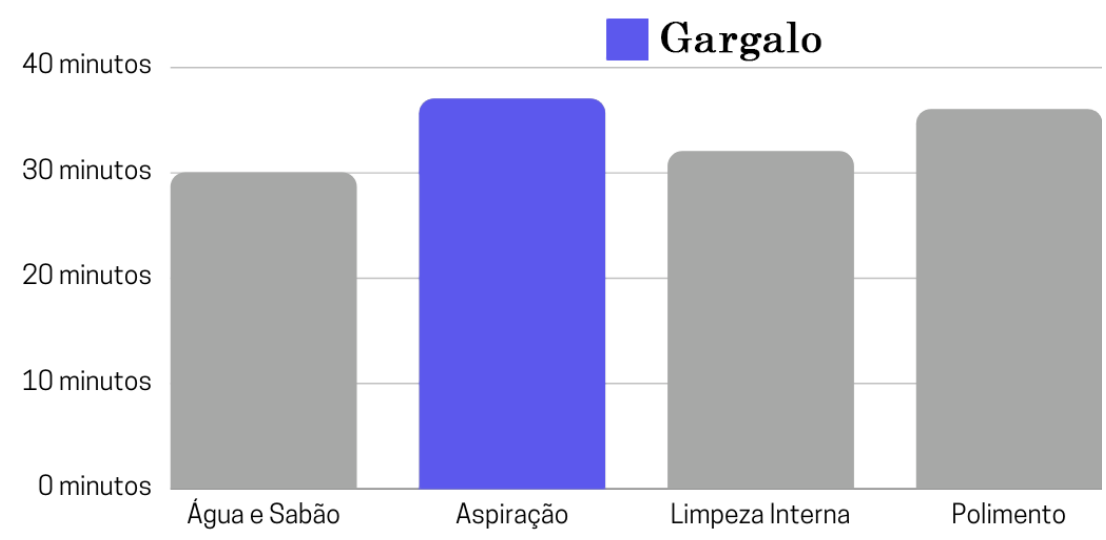

Fonte: Autores (2021).

O processo "Água e Sabão" é 45,31\% mais eficiente e o sistema como todo 31,15\% mais eficiente com tempo total de 
atendimento médio mais veloz cerca de 50 minutos e 23 segundos constatando uma média de 21 veículos atendidos por dia.

É importante considerar que cada aplicação das etapas definidas por Goldratt vai apontar intervenções cada vez mais inflexíveis, ainda mais considerando que as intervenções almejadas neste trabalho não envolvem despesas financeiras. A grosso modo, as intervenções são no sentido de realocar funcionários e até mesmo a organização do espaço produtivo.

Por outro lado, a simulação da intervenção da empresa B também apresentou melhoras significativas no tempo de execução da restrição, inclusive considerando a menor quantidade de trabalhadores. O Quadro 5 a seguir exibe as informações de taxa de utilização da nova simulação da empresa B:

Quadro 5: Relatório Simulação da Intervenção da Empresa B.

\begin{tabular}{|c|c|c|c|}
\hline \multicolumn{4}{|c|}{ Característica Geral do Sistema - Empresa B } \\
\hline \multicolumn{2}{|c|}{ Número médio de atendimento } & \multicolumn{2}{|c|}{12} \\
\hline Tempo & Média & Média Mínima & Média Máxima \\
\hline Tempo de valor agregado & 1hora $23 \min 21 \mathrm{~s}$ & 1 hora $11 \mathrm{~min} 30 \mathrm{~s}$ & 1hora $34 \mathrm{~min} 59 \mathrm{~s}$ \\
\hline Tempo de Espera & $14 \mathrm{~min} 25 \mathrm{~s}$ & 0 & 1hora $23 \mathrm{~min} 55 \mathrm{~s}$ \\
\hline Tempo de Transferência & $4 \mathrm{~min} 58 \mathrm{~s}$ & $4 \min 37 \mathrm{~s}$ & $5 \mathrm{~min}$ \\
\hline Outros & $2 \min 58 \mathrm{~s}$ & $2 \min 38 \mathrm{~s}$ & $3 \mathrm{~min}$ \\
\hline Total Time & 1horas $45 \mathrm{~min} 42 \mathrm{~s}$ & 1 hora $25 \mathrm{~min}$ & 2 horas $58 \mathrm{~min} 53 \mathrm{~s}$ \\
\hline Características específicas & Média & Média Mínima & Média Máxima \\
\hline $\begin{array}{l}\text { Número de entidades que } \\
\text { entraram no sistema }\end{array}$ & 15,813 & 8,0000 & 25,0000 \\
\hline $\begin{array}{l}\text { Número de entidades que } \\
\text { saíram no sistema }\end{array}$ & 12,430 & 5,0000 & 19,0000 \\
\hline $\begin{array}{l}\text { Trabalho em } \\
\text { desenvolvimento }\end{array}$ & 3,175 & 1,468 & 7,363 \\
\hline \multicolumn{4}{|c|}{ Características da Fila } \\
\hline Tempo de Espera & Média & Média Mínima & Média Máxima \\
\hline Água e Sabão & $2 \min 12 s$ & 0 & $15 \mathrm{~min} 36 \mathrm{~s}$ \\
\hline Aspiração & $6 \mathrm{~min} 16 \mathrm{~s}$ & 0 & $35 \mathrm{~min} 41 \mathrm{~s}$ \\
\hline Limpeza Interna & $2 \min 30 s$ & 0 & $20 \mathrm{~min} 14 \mathrm{~s}$ \\
\hline Polimento & $4 \mathrm{~min} 26 \mathrm{~s}$ & 0 & $48 \min 7 \mathrm{~s}$ \\
\hline Tamanho da Fila & Média & Média Mínima & Média Máxima \\
\hline Água e Sabão & 0,077 & 0 & 0,604 \\
\hline Aspiração & 0,206 & 0 & 1,487 \\
\hline Limpeza Interna & 0,077 & 0 & 0,717 \\
\hline Polimento & 0,140 & 0 & 2,005 \\
\hline \multicolumn{4}{|c|}{ Taxa de Utilização dos Recursos - Tempo de Atendimento } \\
\hline Processos & Média & Média Mínima & Média Máxima \\
\hline Água e Sabão & $27 \min 3 \mathrm{~s}$ & $12 \min 10 \mathrm{~s}$ & $43 \mathrm{~min} 35 \mathrm{~s}$ \\
\hline Aspiração & $32 \mathrm{~min} 18 \mathrm{~s}$ & $14 \mathrm{~min} 15 \mathrm{~s}$ & $51 \mathrm{~min} 19 \mathrm{~s}$ \\
\hline Limpeza Interna & $31 \mathrm{~min} 17 \mathrm{~s}$ & $16 \mathrm{~min} 12 \mathrm{~s}$ & $47 \mathrm{~min} 37 \mathrm{~s}$ \\
\hline Polimento & $28 \mathrm{~min} 44 \mathrm{~s}$ & $13 \mathrm{~min} 13 \mathrm{~s}$ & $48 \mathrm{~min} 35 \mathrm{~s}$ \\
\hline
\end{tabular}

Fonte: Autores (2021).

O processo "Água e Sabão" é 44,89\% mais eficiente e o sistema como todo 15,94\% mais eficiente com tempo total de atendimento médio mais veloz 20 minutos e 3 segundos atendendo média de 12 veículos por dia. O Gráfico 4 a seguir representa o gráfico da taxa de utilização dos recursos na nova simulação da empresa B. 
Gráfico 4: Novo Gargalo da Empresa B.

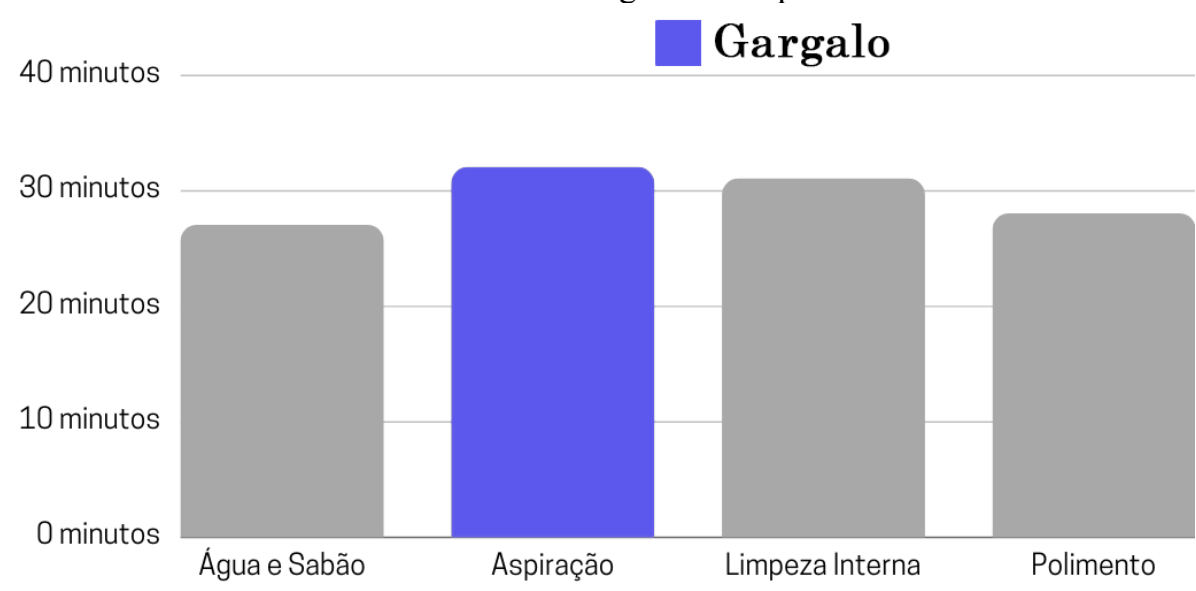

Fonte: Autores (2021).

Analisando o gráfico é possível concluir uma melhora significativa com relação ao tempo de execução do processo Água e Sabão. Além disso, é importante considerar o novo gargalo do sistema apresentando o maior tempo de execução representado é o processo Aspiração.

\section{Considerações Finais}

As ferramentas utilizadas neste estudo se complementam, de modo que a Teoria das Filas contribui para a compreensão da fila na análise do modelo, enquanto a simulação computacional oferece resultados detalhistas do comportamento da matriz de atendimento estudada. Em paralelo, a Teoria das Restrições aponta uma possível intervenção para otimização do modelo. Esses mecanismos empregados de forma recorrente significam uma visão sistêmica do processo produtivo e o autorregulador ao mercado.

A simulação das empresas representou todo o processo da chegada à saída do sistema. Assim, foi possível obter várias informações da empresa que contribuíram para uma visão sistêmica de como é a rotina de trabalho nesta empresa. É possível analisar diversos parâmetros como o número de atendimentos médio por dia, informações relacionadas com tempo de valor agregado ou tempo que o veículo estava sendo processado, tempo de espera, tempo de transferência e o tempo total de atendimento. Além do mais, algumas características específicas da empresa também são logradas no relatório da simulação como, número médio de entidades que entraram no sistema, que saíram do sistema e os que ficaram sendo processados ao final da simulação.

As simulações das intervenções apontaram que é vantajosa a reorganização dos servidores nas empresas e comprovou um avanço significativo no aumento de produção. A empresa A apresentou uma melhora de 45,31\% no tempo de execução do processo "Água e Sabão", e a melhoria do sistema de 31,15\%. Além disso, a empresa B também apresentou bons resultados ao concentrar seus servidores no processo "Água e Sabão", com melhora de 44,89\% do tempo de execução deste processo e a melhoria de $15,94 \%$ do tempo total de atendimento.

Ademais, foi possível determinar novos gargalos para as empresas, e considerar que a reaplicação das etapas definidas por Goldratt significariam intervenções mais inflexíveis, uma vez que neste trabalho são consideradas intervenções sem despesas financeiras.

É sabido que, modelos de fila com processo de chegada e atendimento com variável aleatória não distribuída exponencialmente, ou seja, não representada pela distribuição exponencial e/ou Poisson são considerados modelos complexos. No entanto, grande parte dos possíveis resultados oriundos da aplicação da Teoria das Filas já foram obtidos com os relatórios 
do Arena. De forma geral, a Teoria das Filas é uma ferramenta de descrição de processos de fila e muitos dos seus conceitos são considerados no algoritmo do software Arena.

A Teoria das Filas e a Teoria das Restrições complementam os resultados auferidos com a simulação. Sendo a Teoria das Filas uma ferramenta que auxilia no entendimento do comportamento da Fila, a Teoria das Restrições método para interpretação de como melhorar o sistema estudado e as simulações que permitem representar o modelo com propriedade e testar possíveis intervenções.

Para possíveis trabalhos futuros é imperativo considerar uma amostra ainda maior de dados a fim de executar simulações cada vez mais próximas da realidade. Além do mais, apresentar para o proprietário das empresas em questão a possível aplicação da intervenção no sistema de atendimento real ponderando possíveis riscos e benefícios para tal.

\section{Referências}

Alvarez, M. E. B. (2012). Gestão de qualidade, produção e operação. Atlas.

Banks, J. (2014). Discrete event system simulation. (5a ed.), Pearson Education India.

Bassanezi, R. C. (2002). Ensino-aprendizagem com modelagem matemática: uma nova estratégia. Contexto.

Camelo, G. R., Coelho, A. S., Borges, R. M., \& de Souza, R. M. (2010). Teoria das filas e da simulação aplicada ao embarque de minério de ferro e manganês no terminal marítimo de ponta da madeira. Cadernos do IME-Série Estatística, 29(2), 1.

De Oliveira, W. A. S., Assunção, C. S. D. L. T., \& Gentil, R. F. C. (2020). A teoria das restrições nos processos logísticos na Produção da alimentação escolar: um estudo de caso no setor público. Research, Society and Development, 9(8), e481985497-e481985497.

Doo-Kwon B. (2005). Systems modeling and simulation: theory and applications - third Asian Simulation Conference, AsiaSim 2004, Jeju Island, Korea, October, 2004. Springer.

Figueiredo, J. C. B. D. (2010). Modelo computacional para simulação de aplicação da teoria das restrições. Revista Alcance, 17, $19-31$.

Fogliatti, M. C.\& Mattos, N. M. C. (2007). Teoria de Filas. Editora Interciência.

Freitas Filho, P. J. de. (2001). Introdução à modelagem e simulação de sistemas: com aplicações em Arena. Visual Books.

Goldratt, E. M. (1994) A Meta. (17a ed.), Educator.

Goldratt, E. M. (1990) What is this thing called Theory of Constraints and how should it be implemented? North River Press.

Hermann, W., Juvanelli, C., \& Coqueiro, V. dos S. (2020). Overview of publications on Mathematical Modeling in four journals of the teaching area. Research, Society and Development, 9(8), e73985139. https://doi.org/10.33448/rsd-v9i8.5139.

Kritz, M. V., Silva, J. M., \& Mazza, C. D. (2012) Modelos e Sustentabilidade nas Paisagens Alagáveis Amazônicas. (2a ed.), SBMAC. 34. 100p.

Laure, M. G. (2019) Utilização do software arena student como recurso computacional didático. 101f. dissertação. (Programa de Pós-Graduação Tecnologia, Ambiente e Sociedade - UFVJM) - Instituto de Ciência, Engenharia e Tecnologia. Universidade Federal dos Vales do Jequitinhonha e Mucuri, Teófilo Otoni.

Lacerda, L. P. (2020) Aplicação da modelagem computacional para gestão de sistemas com formação de filas. Trabalho de Conclusão de Curso, Bacharelado em Ciência e Tecnologia - Instituto de Ciência, Engenharia e Tecnologia. Universidade Federal dos Vales do Jequitinhonha e Mucuri, Teófilo Otoni.

Prado, D. (1999) Usando o Arena em Simulação. Editora de Desenvolvimento Gerencial.

Rockwell, A. (1982) Arena Simulation Software. www.arenasimulation.com.

Sabbadini, F. S., Gonçalves, A. A. \& Oliveira M. J. F. de (2006) A aplicação da teoria das restrições (toc) e da simulação na gestão da capacidade de atendimento em hospital de emergência. Revista Produção Online, 6.

Silva, M. J., \& Lacerda, L. P. (2019) Aplicação da modelagem computacional para melhoria do atendimento em uma empresa de lavagem de veículos. Vozes dos Vales, 16, 1-23.

Simmel, G. (1987) A metrópole e a vida mental. In: VELHO, G. (Org.). O fenômeno urbano. Ed. Guanabara.

Venturin, A. C. Z., \& Silva, L. C. da. (2019). Modelagem e simulação da secagem de arroz com casca: uma análise bibliométrica. Research, Society and Development, 8(1), e4881658-e4881658. 